\title{
A Summary of Actinide Enrichment Technologies and Capability Gaps
}

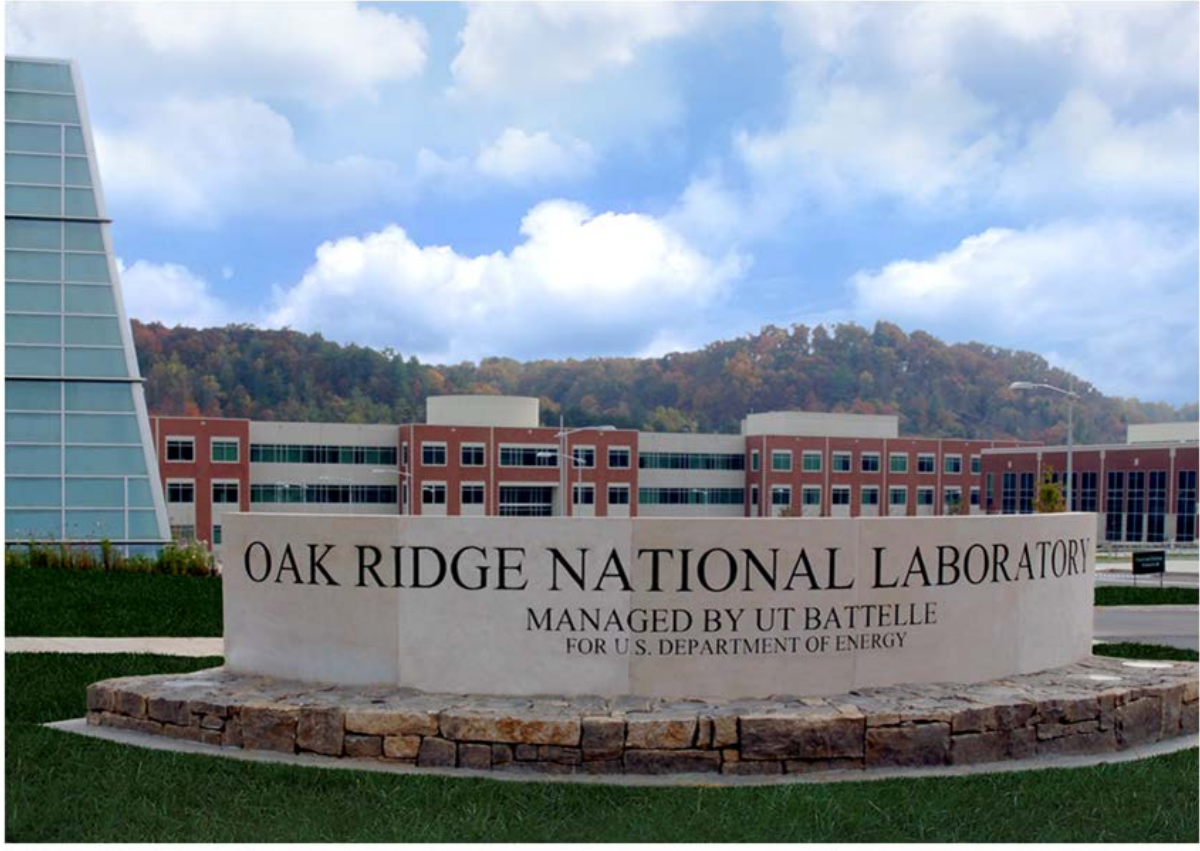

Approved for public release. Distribution is unlimited.

Bradley Patton

Sharon Robinson

January 2017 


\section{DOCUMENT AVAILABILITY}

Reports produced after January 1, 1996, are generally available free via US Department of Energy (DOE) SciTech Connect.

Website http://www.osti.gov/scitech/

Reports produced before January 1, 1996, may be purchased by members of the public from the following source:

National Technical Information Service

5285 Port Royal Road

Springfield, VA 22161

Telephone 703-605-6000 (1-800-553-6847)

TDD 703-487-4639

Fax 703-605-6900

E-mail info@ntis.gov

Website http://classic.ntis.gov/

Reports are available to DOE employees, DOE contractors, Energy Technology Data Exchange representatives, and International Nuclear Information System representatives from the following source:

Office of Scientific and Technical Information

PO Box 62

Oak Ridge, TN 37831

Telephone 865-576-8401

Fax 865-576-5728

E-mail reports@osti.gov

Website http://www.osti.gov/contact.html

This report was prepared as an account of work sponsored by an agency of the United States Government. Neither the United States Government nor any agency thereof, nor any of their employees, makes any warranty, express or implied, or assumes any legal liability or responsibility for the accuracy, completeness, or usefulness of any information, apparatus, product, or process disclosed, or represents that its use would not infringe privately owned rights. Reference herein to any specific commercial product, process, or service by trade name, trademark, manufacturer, or otherwise, does not necessarily constitute or imply its endorsement, recommendation, or favoring by the United States Government or any agency thereof. The views and opinions of authors expressed herein do not necessarily state or reflect those of the United States Government or any agency thereof. 


\title{
A SUMMARY OF ACTINIDE ENRICHMENT TECHNOLOGIES AND CAPABILITY GAPS
}

\author{
Bradley Patton \\ Sharon Robinson
}

Date Published: January 2017

Prepared by

OAK RIDGE NATIONAL LABORATORY

Oak Ridge, TN 37831-6283

managed by

UT-BATTELLE, LLC

for the

U.S. DEPARTMENT OF ENERGY

under contract DE-AC05-00OR2275 



\section{CONTENTS}

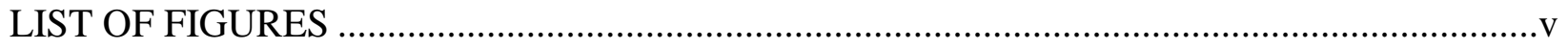

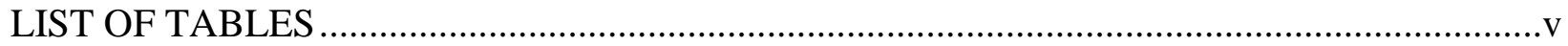

ACRONYMS AND ABBREVIATIONS ....................................................................... vii

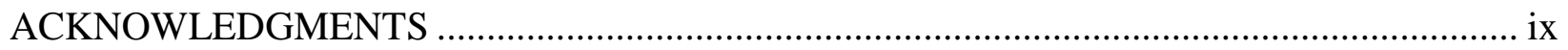

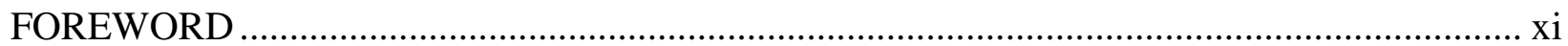

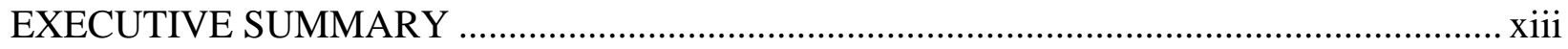

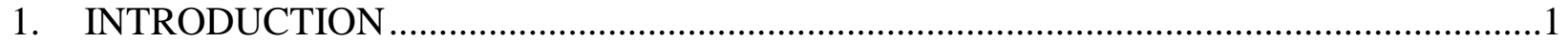

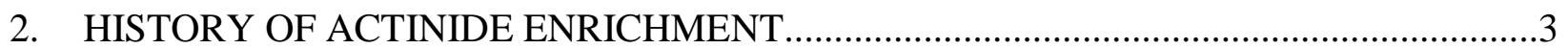

2.1 ELECTROMAGNETIC ISOTOPE SEPARATION ................................................

2.1.1 ORNL Calutron Electromagnetic Isotope Enrichment Facility ........................3

2.1.2 Former USSR Calutron Electromagnetic Isotope Enrichment Facilities ............6

2.1.3 Idaho Scandinavian Electromagnetic Isotope Enrichment Facility ...................9

2.1.4 Pacific Northwest National Laboratory Inductively Coupled Plasma Mass

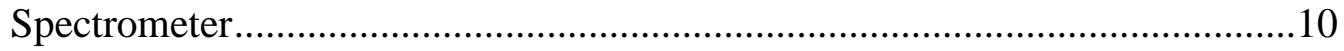

2.1.5 ORNL Enriched Stable Isotope Production Facility ....................................11

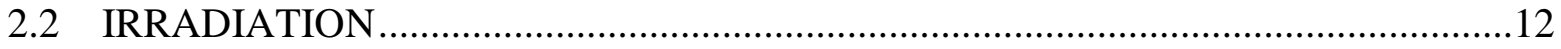

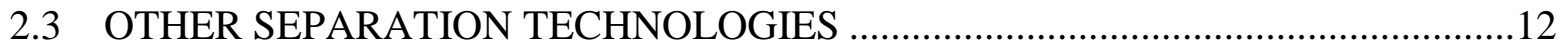

2.3.1 Gaseous Centrifuge ............................................................................13

2.3.2 Laser and Plasma Separations ..............................................................13

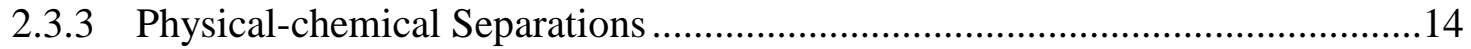

3. POTENTIAL TECHNOLOGIES FOR FUTURE ACTINIDE ENRICHMENT .................15

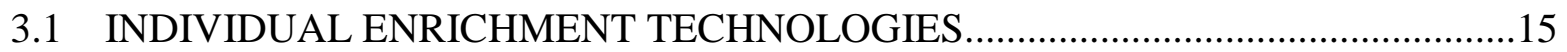

3.2 COMBINED ENRICHMENT TECHNOLOGIES ................................................ 16

4. ACTINIDE ENRICHMENT REQUIREMENTS ........................................................19

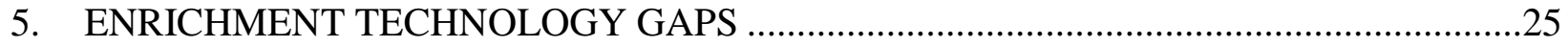

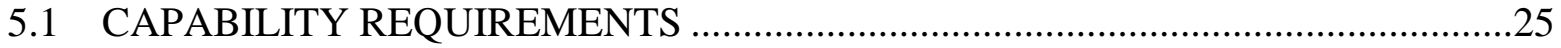

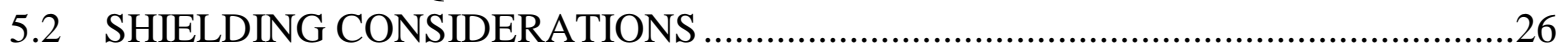

5.3 PRE- AND POST ENRICHMENT REQUIREMENTS ...........................................26

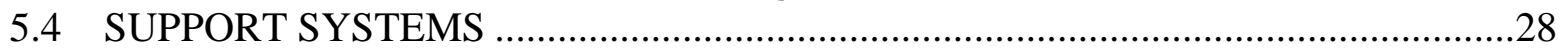

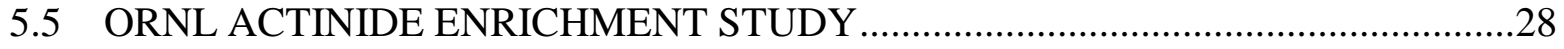

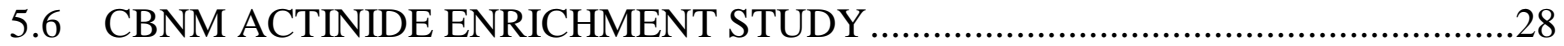

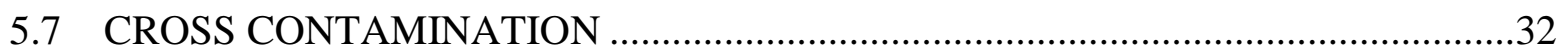

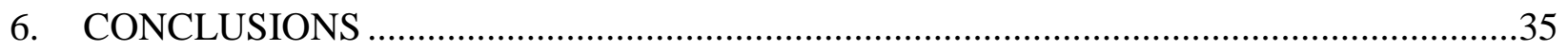

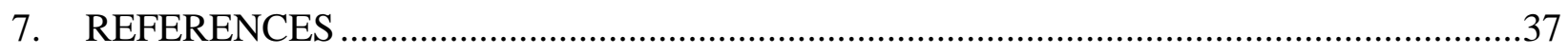





\section{LIST OF FIGURES}

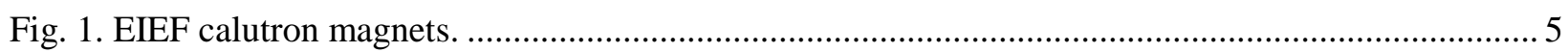

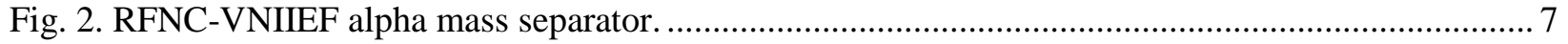

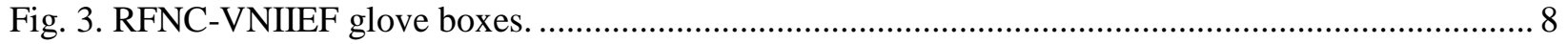

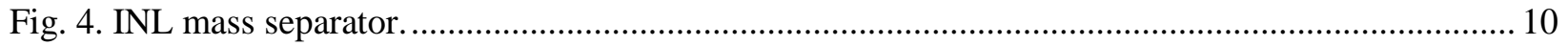

Fig. 5. ORNL EMIS device. ....................................................................................... 12

Fig. 6. Amount of ${ }^{242} \mathrm{Pu}$ allowed in a DOE radiological facility as a function of enrichment. .................. 22

Fig. 7. Existing enrichment capabilities compared to future requirements....................................... 25

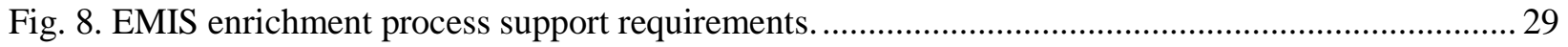

Fig. 9. Concept for an actinide isotope separator (Berg et al. 1985)................................................30

Fig. 10. Sequence of operations in an actinide handling facility (Berg et al. 1985)............................. 31

Fig. 11. Concept for equipment layout for an actinide handling facility (Berg et al. 1985).................... 33

\section{LIST OF TABLES}

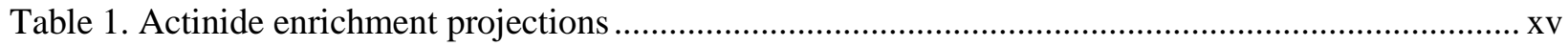

Table 2. Isotope content of highly enriched actinides produced in EIEF ….............................................. 6

Table 3. Isotope content of highly enriched materials produced by RFNC-VNIIEF................................. 8

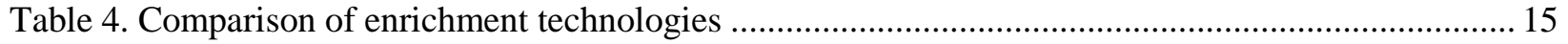

Table 5. Cost effectiveness of isotopes enrichment processes.................................................................. 16

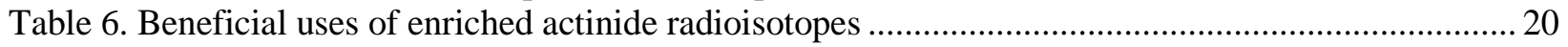

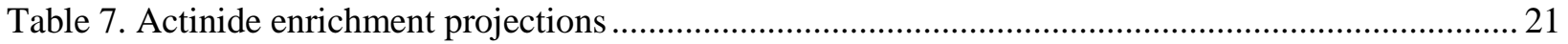

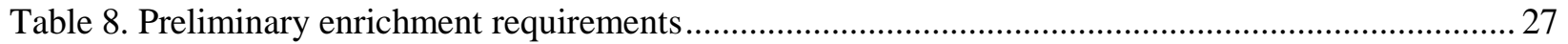





\section{ACRONYMS AND ABBREVIATIONS}

$\begin{array}{ll}\text { AIS } & \text { Advanced Isotope Separation } \\ \text { AVLIS } & \text { Atomic Vapor Laser Isotope Separation } \\ \text { CBNM } & \text { Central Bureau for Nuclear Measurements } \\ \text { CRM } & \text { Certified Reference Material } \\ \text { DOE } & \text { US Department of Energy } \\ \text { EIEF } & \text { Electromagnetic Isotope Enrichment Facility } \\ \text { EMIS } & \text { Electromagnetic Isotope Separation } \\ \text { ESIPP } & \text { Enriched Stable Isotope Pilot Plant } \\ \text { GCIS } & \text { Gas Centrifuge Isotope Separation } \\ \text { HFIR } & \text { High Flux Isotope Reactor } \\ \text { IAEA } & \text { International Atomic Energy Agency } \\ \text { ICP-MS } & \text { inductively coupled plasma mass spectrometer } \\ \text { IDMS } & \text { isotope dilution mass spectrometry } \\ \text { MLIS } & \text { Molecular Laser Isotope Separation } \\ \text { INL } & \text { Idaho National Laboratory } \\ \text { ONMI } & \text { DOE National Nuclear Security Administration Office of Nuclear Materials } \\ & \text { Integration } \\ \text { ORNL } & \text { Oak Ridge National Laboratory } \\ \text { PNNL } & \text { Pacific Northwest National Laboratory } \\ \text { PSP } & \text { Plasma Separation Process } \\ \text { R\&D } & \text { research and development } \\ \text { RFNC-VNIIEF } & \text { Russian Federal Nuclear Center-All Russian Scientific Research Institute for } \\ & \text { Experimental Physics Enrichment Facility } \\ \text { SHE } & \text { super-heavy element } \\ \text { US } & \text { United States } \\ \text { USSR } & \text { Union of Soviet Socialist Republics }\end{array}$





\section{ACKNOWLEDGMENTS}

The authors gratefully acknowledge the sponsorship of the Department of Energy National Nuclear Security Administration Office of Nuclear Materials Integration (NA-532). The authors thank the many people who provided input to the analyses, including Scott Aaron, Rose Boll, Emory Collins, Dan Ilas, Ben Lewis, Catherine Romano, Krzysztof Rykaczewski, and Joe Tracy. 



\section{FOREWORD}

The objective of this report is to summarize technologies that have been used or considered for isotopic enrichment of actinides and identify current capability gaps based on an informal assessment of user needs to support national security, nuclear nonproliferation, and basic research programs. . The technology and potential needs for enrichment of ${ }^{235} \mathrm{U}$ are excluded from consideration in this report. The report focuses on the enrichment requirements for highpurity actinide materials to meet the needs of nuclear forensics and research programs in the United States. The report is designed to be a useful strategic planning tool that can contribute to plans for reestablishing radioisotope enrichment capabilities in the United States.

The information for this report was obtained through a variety of sources, including open literature technical documents and canvasing users with science and technology needs. While this report presents a compilation of actinide enrichment gaps and opportunities, the datagathering activities were limited by time, scope, participation, and boundaries imposed on the subject area. As a result, the report may not fully capture all radioisotope enrichment technologies, requirements, and viewpoints. Although efforts were made to incorporate a broad range of information, it is inevitable that valuable ideas may have been left out. Thus, this document contains information from a "snapshot in time" that can be used as input to future efforts to reestablish domestic capabilities for production of high purity radioisotopes to support requirements for nuclear forensics or basic research. 



\section{EXECUTIVE SUMMARY}

The United States (US) has not had the capability to enrich radioisotopes to support the needs of national security, nuclear nonproliferation and basic research programs since 1979 when the operation of the Oak Ridge National Laboratory (ORNL) actinide calutrons ended. Because the capability to enrich milligram-to-gram quantities of actinide radioisotopes no longer exists in the United States, the enriched actinide needs of the nation currently are not being met or are being met using existing, but diminishing, domestic inventories and foreign (mostly Russian) sources where available.

The dwindling supply of existing inventory and the unavailability of future domestic and international sources are of concern to users of actinides for applications in national security, nuclear nonproliferation, and basic research programs. For example, the current inventory of enriched ${ }^{244} \mathrm{Pu}$ will be depleted in the near future. In fact, several standards organizations, such as New Brunswick Laboratory and the Institute for Reference Materials and Measurements, have stopped or severely limited distribution of their ${ }^{244} \mathrm{Pu}$ standards to conserve the remaining small quantities (milligram level) for very high priority needs. Without additional supplies of enriched

${ }^{244} \mathrm{Pu}$, the United States, the International Atomic Energy Agency, and others risk losing certain measurement capabilities that are essential in maintaining an active nuclear forensics and safeguards posture in current and future world affairs.

These concerns resulted in a 2001 task force, headed by the former US Department of Energy (DOE) Secretary of Energy Ernest Moniz, designating the existing inventory of ${ }^{244} \mathrm{Pu}$ as a national resource material and recommending that alternative technologies should be identified and developed to separate and enrich these materials (Moniz 2001). The DOE National Nuclear Security Administration Office of Nuclear Materials Integration (ONMI) initiated a program in 2016 to recover and separate the world's supply of ${ }^{244} \mathrm{Pu}$ (Robinson et al. 2014) as the task force recommended. This report is the first step toward meeting the task force recommendation to identify potential technologies that might effectively enrich the materials for programmatic use.

The US inventory of enriched actinides was produced via electromagnetic isotope separation (EMIS) in the ORNL calutrons until they were shut down in 1979. Significant strides have been made recently in the development of new and improved stable isotope enrichment technologies to replace techniques first used in World War II. The effort summarized in this report was undertaken to document state of the art of radioisotope enrichment capabilities and identify the basic requirements for future actinide enrichment capabilities based on the information collected during the preparation of this report.

The evaluation performed in this study indicates that a new program is needed to efficiently provide a national actinide radioisotope enrichment capability to produce milligram-to-gram quantities of unique materials for user communities as summarized in Table 1. This program 
should leverage past actinide enrichment, the recent advances in stable isotope enrichment, and assessments of the future requirements to cost effectively develop this capability while establishing an experience base for a new generation of researchers in this vital area. Preliminary evaluations indicate that an EMIS device would have the capability to meet the future needs of the user community for enriched actinides. The EMIS technology could be potentially coupled with other enrichment technologies, such as irradiation, as pre-enrichment and/or postenrichment systems to increase the throughput, reduce losses of material, and/or reduce operational costs of the base EMIS system. Past actinide enrichment experience and advances in the EMIS technology applied in stable isotope separations should be leveraged with this new evaluation information to assist in the establishment of a domestic actinide radioisotope enrichment capability. 
Table 1. Actinide enrichment projections

\begin{tabular}{|c|c|l|c|c|}
\hline $\begin{array}{c}\text { Enriched } \\
\text { Actinide }\end{array}$ & \multicolumn{1}{|c|}{ Use } & \multicolumn{1}{c|}{ Users } & $\begin{array}{c}\text { Isotopic Purity } \\
\text { Desired }\end{array}$ & $\begin{array}{c}\text { Maximum Quantity } \\
\text { Desired Over a 5 Year } \\
\text { Period }\end{array}$ \\
\hline${ }^{236} \mathrm{~Np}$ & Nuclear forensics & $\begin{array}{l}\text { Department of Homeland Security } \\
\text { Department of Energy } \\
\text { Defense Threat Reduction Agency } \\
\text { Intelligence Community } \\
\text { International Atomic Energy Agency }\end{array}$ & $99.99 \%$ & $1-2 \mathrm{mg}$ \\
\hline${ }^{242} \mathrm{Pu}$ & $\begin{array}{c}\text { Super heavy element } \\
\text { (SHE) research \& } \\
\text { plutonium research }\end{array}$ & $\begin{array}{l}\text { Department of Energy SHE Research Community } \\
\text { National Nuclear Security Administration }\end{array}$ & $99-99.9 \%$ & $\begin{array}{c}>200 \mathrm{mg} \text { for SHE } \\
\text { research } \\
\text { TBD plutonium } \\
\text { research }\end{array}$ \\
\hline${ }^{244} \mathrm{Pu}$ & $\begin{array}{c}\text { SHE research \& } \\
\text { nuclear forensics }\end{array}$ & $\begin{array}{l}\text { Department of Homeland Security } \\
\text { Department of State } \\
\text { Defense Threat Reduction Agency } \\
\text { Intelligence Community } \\
\text { International Atomic Energy Agency } \\
\text { Department of Energy SHE Research Community }\end{array}$ & $99.9-99.99 \%$ & $2-5 \mathrm{~g}$ \\
\hline${ }^{244} \mathrm{Cm}$ & SHE Research & Department of Energy SHE Research Community & & $220-500 \mathrm{mg}$ \\
\hline${ }^{248} \mathrm{Cm}$ & SHE Research & Department of Energy SHE Research Community & $99.9 \%$ & $650 \mathrm{mg}$ \\
\hline${ }^{251} \mathrm{Cf}$ & SHE Research & Department of Energy SHE Research Community & $99.9 \%$ & $650 \mathrm{mg}$ \\
\hline
\end{tabular}





\section{INTRODUCTION}

The actinide radioisotopes reside with 15 chemical elements with atomic numbers ranging from 89 to 103 (actinium through lawrencium). With the exception of ${ }^{232} \mathrm{Th},{ }^{235} \mathrm{U}$, and ${ }^{238} \mathrm{U}$, which occur naturally in substantial quantities, the actinide radioisotopes are produced synthetically by irradiation in nuclear reactors, generally with low isotopic purity. The isotopes of interest then must be enriched, often with isotopic purities in the 99-99.99\% range, to obtain the purity required for user applications in national security, nuclear nonproliferation, and basic research programs. This report documents the state of the art of radioisotope enrichment capabilities, identifies the current capability gaps for synthetically produced radioactive actinides, and proposes the basic requirements for future actinide enrichment capabilities. The technology and potential needs for enrichment of ${ }^{235} \mathrm{U}$ is excluded from consideration in this report. Rather the report focuses on the enrichment needs for high-purity actinide materials to support United Sates (US) research and nuclear forensics. The actinide ${ }^{244} \mathrm{Pu}$ will be used as a specific example throughout this document.

The US inventory of enriched actinides that are being used today was produced in the Oak Ridge National Laboratory (ORNL) calutron facilities. These facilities produced gram quantities of numerous valuable enriched actinide isotopes prior to being shut down in 1979. Because the capability to enrich milligram-to-gram quantities of actinide radioisotopes no longer exists in the United States, the enriched actinide needs of the nation currently are being met using existing, but diminishing, domestic inventories and foreign (mostly Russian) sources where available. In some cases, the inventory of highly enriched actinides has been completely depleted. Attempts for over a decade to obtain critical supplies from foreign sources have been unsuccessful. A two decade-long effort to have the Russian Federal Nuclear Center - All Russian Scientific Research Institute for Experimental Physics Enrichment Facility (RFNC-VNIIEF) enrich ${ }^{244} \mathrm{Pu}$ - an actinide material of interest to the United States and the International Atomic Energy Agency (IAEA) - was put on indefinite hold in 2012 after limited enrichment of only a small test quantity. The dwindling supply of existing domestic inventory and the unavailability of future domestic and international sources are of concern.

The unavailability of high-purity ${ }^{244} \mathrm{Pu}$ for use as a reference material for high-precision, destructive analysis techniques, such as isotope dilution mass spectrometry (IDMS), is of particular concern. These analytical techniques are needed for supporting research and development (R\&D) efforts and detecting clandestine activities, as well as for international safeguards efforts due to the expanded use of nuclear fuels for power production. Certified reference materials (CRMs) are an essential part of the nuclear materials control and accountability system. Together with analytical procedures, they provide assurance that the measured amounts of nuclear materials are accurate and traceable. There exists a real need to produce nuclear CRMs that meet the needs of the safeguards and nonproliferation communities for ensuring measurements that meet accuracy and precision goals. Several standards 
organizations, including New Brunswick Laboratory and the Institute for Reference Materials and Measurements, have stopped or severely limited distribution of their ${ }^{244} \mathrm{Pu}$ standards to conserve the remaining small quantities (milligram level) for very high priority needs. Without additional supplies of enriched ${ }^{244} \mathrm{Pu}$, the United States, the IAEA, and others risk losing certain measurement capabilities that are highly essential in maintaining an active nuclear forensics and safeguards posture in current and future world affairs.

DOE implemented a budgetary policy in the 1970s that required full cost recovery for the selling of enriched isotopes for non-programmatic needs. Subsequently, decreased programmatic funding and competition from Russian sources for commercial sales caused operation of the Oak Ridge calutron facility for actinide production to be shut down in 1979. This stopped the domestic production of enriched radioisotopes. Because of the large costs associated with restart of the calutrons, they are not expected to be available in the future for actinide enrichment.

Significant strides have been made in the development of new and improved enrichment technologies since the shutdown of the ORNL calutron facilities. These technologies are primarily being developed for stable isotope enrichment through the DOE Office of Science, Office of Nuclear Physics, Isotope Development and Production for Research and Applications Program (the DOE Isotope Program) and/or for radioisotope enrichment in very small to moderate quantities at ORNL and other US national laboratories. These new technologies could allow gram quantities of radioisotopes to be produced in the future at a more reasonable cost than the previous World War II era enrichment operations. This report summarizes the status of these technologies and identifies gaps in the actinide enrichment capabilities that need to be filled to successfully address potential needs. A technical path forward for reestablishing actinide enrichment capabilities in the United States is suggested. 


\section{HISTORY OF ACTINIDE ENRICHMENT}

There have been only two known sources of enriched radioisotopes produced in multi-gram quantities in the world: (1) The Electromagnetic Isotope Enrichment Facility (EIEF) located in Oak Ridge, Tennessee and (2) Russian facilities, primarily the RFNC-VNIIEF (Tracy and Aaron 1993). These facilities used electromagnetic isotope separation (EMIS) to produce both stable and radioactive enriched isotopes in large quantities. These EMIS processes are described below. Other separation technologies have been considered as alternatives to the electromagnetic separators, primarily for the production of stable isotopes. Of these, only irradiation has been used to produce gram quantities of these actinides. These technologies are also summarized below.

\subsection{ELECTROMAGNETIC ISOTOPE SEPARATION}

EMIS exploits the difference in the bending radii of equal energy ions of different masses in a dipole magnetic field to enrich isotopes. EMIS technology is applicable to most multi-isotope elements in the periodic table (Love 1973). It has been used to produce isotopic purities ranging from a few times natural abundance to purity levels in which unwanted isotopes are present in no more than tenths of a part per billion. Impurities consisting of isotopes separated by one mass unit have, on special occasions, been confined to less than 1 part-per-million and, in some cases, to the parts-per-billion range. Enrichment factors for various isotopes range from about 30 to as high as 80,000 in a single pass.

Present-day EMIS devices can loosely be grouped into two general categories: The high-current production separators (calutron type), and low-current isotope separators associated with laboratory or university research (sometimes referred to as Scandinavian units) (Whitehead and White 1973). The latter are typically capable of producing only milligram quantities and typically focus on production of stable isotopes. Several calutron-type separators were constructed in the United States, Russia, France, and Great Britain after World War II. These separators were designed and built for higher throughput than laboratory machines. Only the historical US and Russian EMIS facilities that have been used to separate radioactive isotopes are discussed in this report. Examples of recent small-scale separators that have improved on the traditional separator technology are also included.

\subsubsection{ORNL Calutron Electromagnetic Isotope Enrichment Facility}

The EIEF was built in the 1940s and was used for the separation of ${ }^{235} \mathrm{U}$ as part of the wartime effort. More than 1000 electromagnetic high-current separators, using mass spectrometer technology and known as calutrons, were built and operated to enrich the ${ }^{235} \mathrm{U}$ used in the first atomic weapons. After more efficient methods of enriching uranium were developed, all but 76 calutrons were decommissioned (Egle et al. 2014). These calutrons were converted to enrich 
stable and selected radioactive isotopes or for plasma and ion source research activities. Two major modifications were made to the original separation facility, which consisted of calutrons contained in two 30.5-m-long magnetic tracks (Tracy et al. 1987; Newman 1979). These modifications included altering one track for stable isotope enrichment and a part of the second track for radioisotopes separations.

Figure 1 is a photograph of the EIEF. The track shown in the foreground was used to enrich stable isotopes, and the track shown in the extreme background contained the eight calutrons which were housed in a containment area and were used for enrichment of selected radioactive isotopes, primarily actinides (Tracy 1991). For the processing of alpha emitting materials, the first-line of containment was a glove box or the calutron itself, and the second-line of containment was an $8000-\mathrm{ft}^{2}$ area, held at reduced atmospheric pressure, in which all processing was done (Love 1973). The elements separated in the EIEF included lithium, boron, carbon, magnesium, silicon, sulfur, chlorine, potassium, calcium, titanium, vanadium, chromium, iron, nickel, copper, zinc, gallium, germanium, selenium, bromine, rubidium, strontium, zirconium, molybdenum, ruthenium, palladium, silver, cadmium, indium, tin, antimony, tellurium, barium, lanthanum, hafnium, tantalum, tungsten, rhenium, osmium, iridium, platinum, mercury, thallium, lead, cerium, neodymium, samarium, europium, gadolinium, dysprosium, erbium, ytterbium, lutetium, thorium, uranium, plutonium, americium, and curium.

The EIEF enrichment process is summarized below. The initial step in the enrichment process was the preparation of a suitable feed-material, in either elemental or compound form, for introduction into the calutron where it was either directly vaporized or heated in a stream of carbon-tetrahalide to form a volatile halide (Newman 1983). The vaporized material was then introduced into an arc discharge where it was ionized in the high-current source. The ionized particle was extracted from the ion source and accelerated to approximately $40 \mathrm{keV}$, bent 180 degrees in a magnetic field, and the individual isotopic beams intercepted by isotope collectors. The collectors (one for each isotope) were located behind a slotted face plate. After a run (or series of runs) whose duration may be from 50 to $>200 \mathrm{~h}$, depending on the element, the collectors were removed from the separator and the enriched product was recovered, chemically purified, assayed, and made available for use.

Each EIEF separator could provide approximately $0.1 \mathrm{~mol}$ of an element per operational day. This figure must be multiplied by the natural isotopic abundance to determine the yield for a particular isotope. Achievable isotopic purity from one separation through the calutrons can be estimated by applying a decontamination factor. The ratio of the final assay divided by the contamination to the initial assay divided by the contamination is given approximately by 23,000 divided by the mass of the isotope. For example, applying this in the lead region yields a decontamination factor on the order of 100 . This would predict that a $5 \%$ initial abundance isotope could be enriched to approximately the $85 \%$ level in a single pass with the standard calutron. 


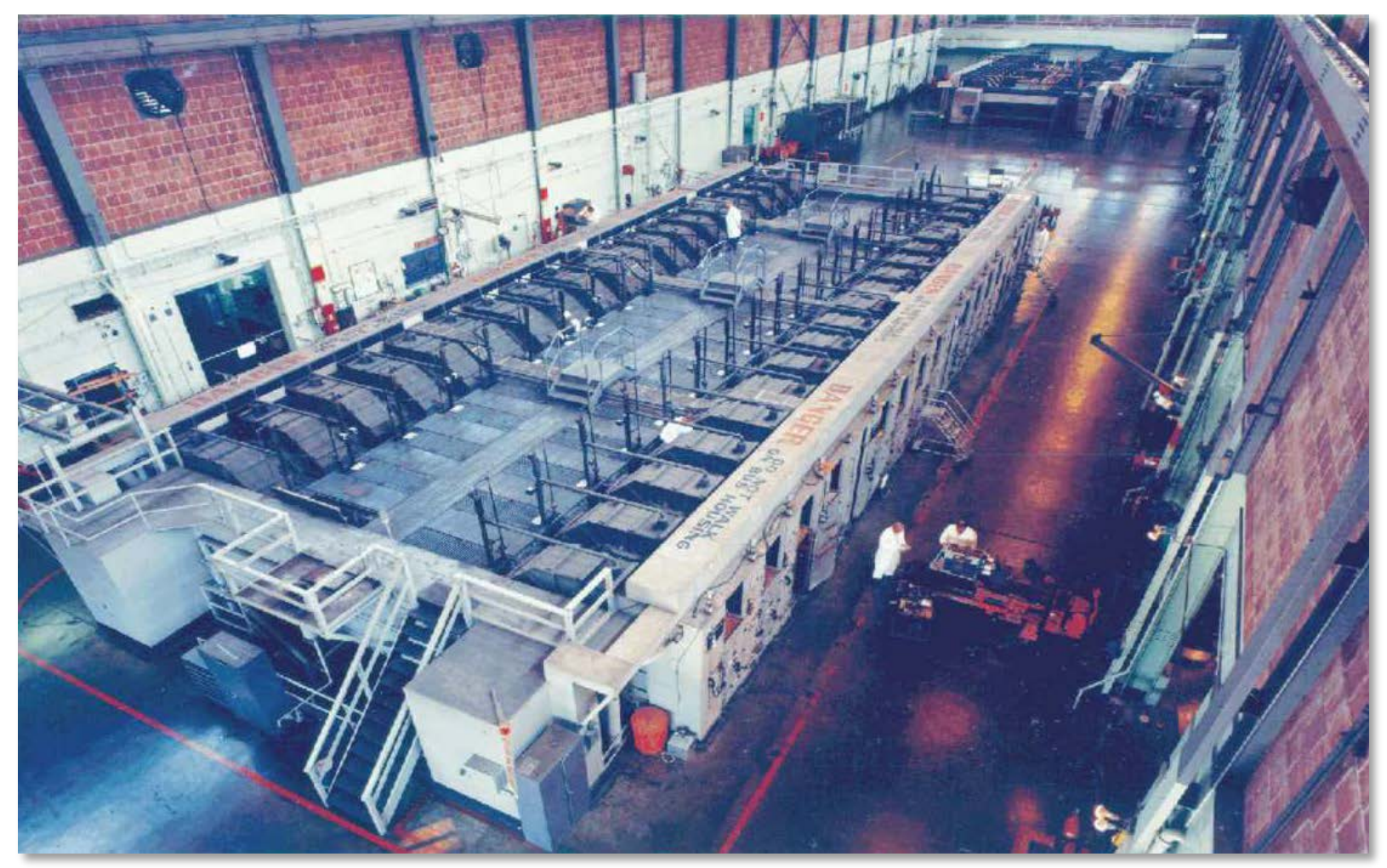

Fig. 1. EIEF calutron magnets.

The products from one separation could be recycled to obtain a significantly higher isotopic assay in a two-pass campaign. This concept was expensive since the process efficiency was significantly less than one. The process efficiency is defined as the ratio of the quantity of material removed from the collectors to the quantity of the charge material vaporized. It was typically between 5 and 25\%, with the average being approximately $10 \%$.

A budgetary policy was implemented in the 1970s that required DOE to sell enriched isotopes at full cost recovery for non-programmatic needs. Subsequently, decreased programmatic funding, increased regulatory compliance costs, and competition from Russian sources for commercial sales caused operation of the Oak Ridge EIEF for actinide production to be shut down in 1979, and those used for stable isotopes were discontinued in 1998. In the 53 years of operation (1945 to 1998), approximately $200 \mathrm{~kg}$ of 233 stable isotopes of 54 elements and 19 radioactive isotopes was produced for a broad variety of beneficial applications (Egle 2014). The radioisotope calutrons were operated to enrich the radioisotopes as summarized in Table 2. Most of the feed materials were produced in reactors. Some materials underwent two passes, and a few underwent three passes, to obtain the isotopic purities shown in Table 2.

Much effort was put into improving the process efficiencies and reducing the costs of stable isotope enrichment in the latter years of the calutron operations (Tracy and Terry 1985). This 
Table 2. Isotope content of highly enriched actinides produced in EIEF

\begin{tabular}{|c|c|c|}
\hline Isotope & Product Purity, at.\% & Quantities Produced, mg \\
\hline${ }^{230} \mathrm{Th}$ & $80.1-99.963$ & 133,013 \\
\hline${ }^{238} \mathrm{Pu}$ & $99.4-99.998$ & 5420 \\
\hline${ }^{239} \mathrm{Pu}$ & $73.5-99.999$ & 431,700 \\
\hline${ }^{240} \mathrm{Pu}$ & $98.3-99.994$ & 704,900 \\
\hline${ }^{241} \mathrm{Pu}$ & $93.2-99.86$ & 190,860 \\
\hline${ }^{242} \mathrm{Pu}$ & $81.9-99.9$ & 835,300 \\
\hline${ }^{244} \mathrm{Pu}$ & $14.6-98.6$ & 7528 \\
\hline${ }^{242 \mathrm{~m}} \mathrm{Am}$ & 21.1 & 70 \\
\hline${ }^{245} \mathrm{Cm}$ & $12-76.5$ & 12 \\
\hline${ }^{246} \mathrm{Cm}$ & $87.7-95.4$ & 37 \\
\hline${ }^{247} \mathrm{Cm}$ & $21.2-30.1$ & 1 \\
\hline${ }^{248} \mathrm{Cm}$ & $45.5-54.7$ & 1 \\
\hline
\end{tabular}

included adding a multi-element separation technique where the isotopes of more than one element were processed in one segment simultaneously.

\subsubsection{Former USSR Calutron Electromagnetic Isotope Enrichment Facilities}

The former Union of Soviet Socialist Republics (USSR) developed electromagnetic separation processes at several facilities across the country. Since the mid-1970s, the production of middle and heavy mass stable isotopes was carried out primarily at the enterprise Electrokhimpribor (Svedlovsk region) where up to 20 SU-20 industrial electromagnetic separators were located (Pokidychev and Pokidycheva 1999). In the late 1980s, production switched toward isotopes for medical applications for export, which had only been a small part of the total volume up to that time. The Kurchatov Institute in Moscow used two separators for the production of stable isotopes beginning in 1989. The separation of most light isotopes was centered at the Research Institute of Stable Isotopes (Tbilisi) in Georgia (Pokidychev and Pokidycheva 1999).

A four-chamber electromagnetic isotope separator was constructed at the Russian Research Center Kurchatov Institute in the 1940s and was used to separate more than 40 elements from magnesium up to uranium (Kouzmine et al. 1999). In 1989, two chambers were reconstructed, replacing the homogeneous magnetic field with a field which falls off on the radius (r) at 1/r. This increased the dispersion by a factor of four and increased the enrichment of the isotopes significantly.

The SU-20 electromagnetic separator facility at Electrokhimpribor was put into operation in 1951 and was used until 1955 for processing uranium and lithium. Regular stable isotope separation began in 1955, and 200 isotopes of 44 elements had been produced up to 1989. The equipment specifications and the general scheme of the production process have been documented (Kaschejev et al. 1993). 
The RFNC-VNIIEF (in Sarov, Russia) laboratory was equipped with electromagnetic separation capabilities specifically designed for enriching milligram-to-gram quantities of alpha-active transuranium element isotopes in 1967 (Vesnovskii and Polynoc 1992; Vesnovskii 2003; Vesnovskii 2004). It contains a mass-separator, S-2 type, equipped with personnel radiation protection required for the production of enriched actinides (Abramychev et al. 1992) as shown in Figures 2 and 3 (Vesnovskii et al 1992). The original unit used $\sim 1 \mathrm{~g}$ quantities of anhydrous trichlorides of the actinide elements as the working substance. The efficiency for one separation cycle was $\sim 5 \%$ of the initial mass with all isotopes of the element being separated accumulating simultaneously in the isotope receivers which are made of super pure copper or aluminum. The isotopes are collected with the help of nitric or hydrochloric acids. The facility was designed to enrich uranium, plutonium, americium, and curium. The purity of the enriched actinides and the quantities of the materials available in 1992 are documented by Vesnovskii and Polynov (1992) and are summarized in Table 3. Vesnovskii et al. (1996) reported that the lower values in the range of isotopic purity of several of the elements shown in Table 3 were achieved after a single separation and the higher purity levels were achieved after two separations. Vesnovskii (2004) reported the same enrichment capabilities in 2004.

A two decade-long effort to have the RFNC-VNIIEF enrich US-produced ${ }^{244} \mathrm{Pu}$ resulted in $0.88 \mathrm{mg}$ of enriched plutonium product (Penkin et al. 2015). The recovered tails from enrichment

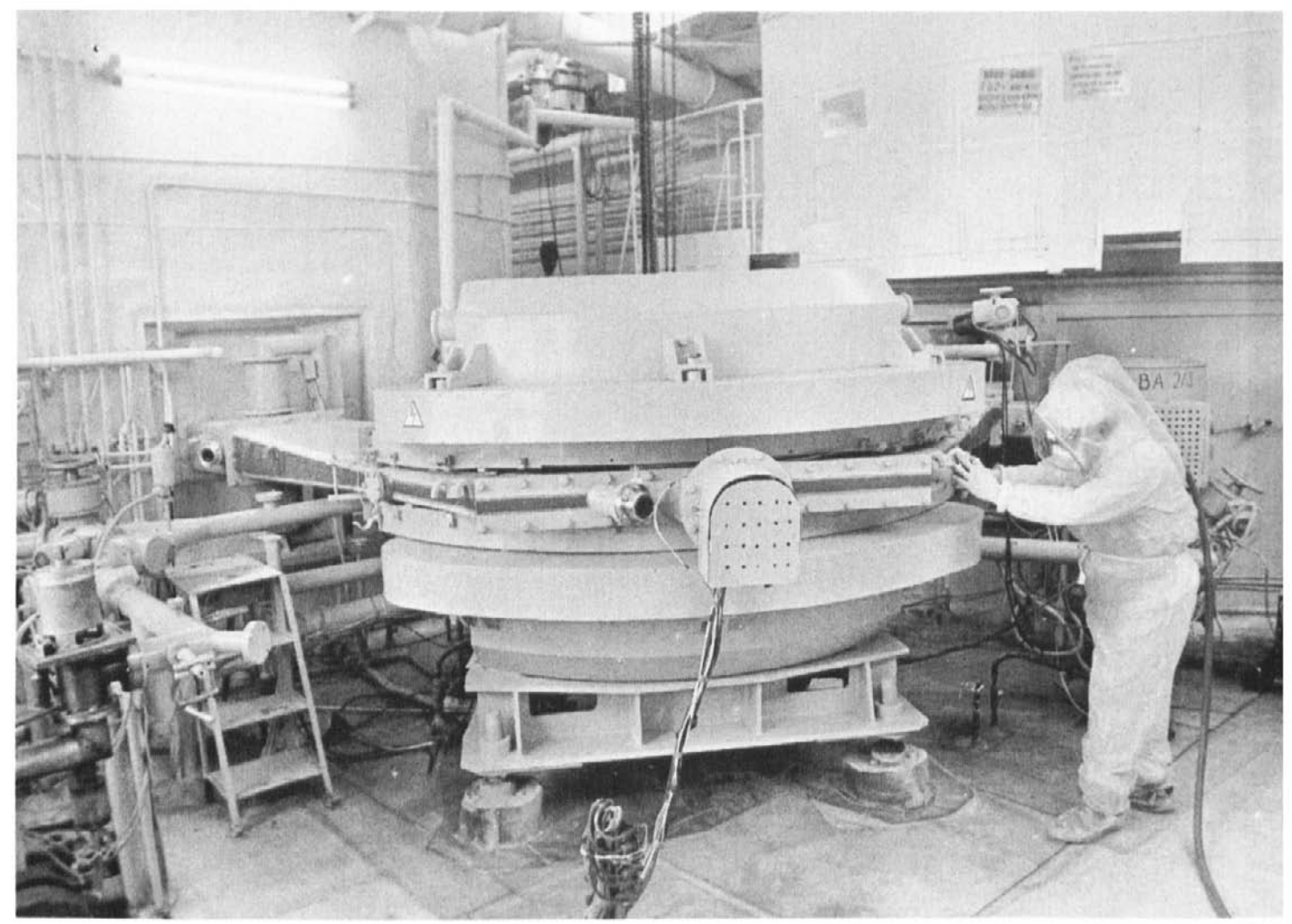

Fig. 2. RFNC-VNIIEF alpha mass separator. 


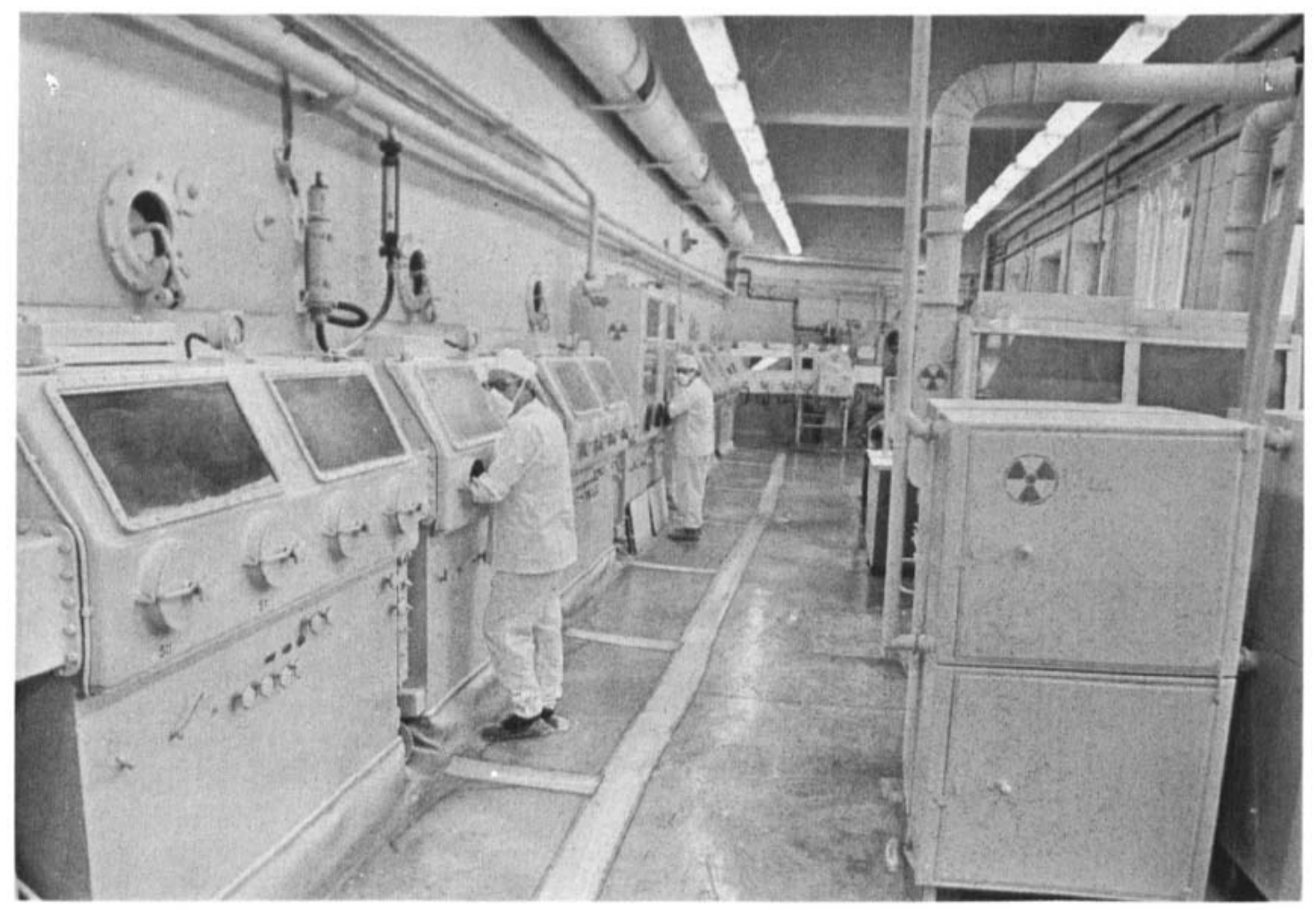

Fig. 3. RFNC-VNIIEF glove boxes.

Table 3. Isotope content of highly enriched materials produced by RFNC-VNIIEF

\begin{tabular}{|c|c|c|}
\hline Isotope & Product Purity, at.\% & Quantities Available in 1992, mg \\
\hline${ }^{238} \mathrm{Pu}$ & 99.6 & 20 \\
\hline${ }^{239} \mathrm{Pu}$ & $99.5-99.997$ & 200 \\
\hline${ }^{240} \mathrm{Pu}$ & $90.7-99.9$ & 50 \\
\hline${ }^{241} \mathrm{Pu}$ & $99.6-99.998$ & 150 \\
\hline${ }^{242} \mathrm{Pu}$ & $97.8-99.99$ & 100 \\
\hline${ }^{244} \mathrm{Pu}$ & $97.8-98.9$ & 0.01 \\
\hline${ }^{241} \mathrm{Am}$ & 99.99 & 200 \\
\hline${ }^{242} \mathrm{Am}$ & $55.1-85.6$ & 2.0 \\
\hline${ }^{243} \mathrm{Am}$ & $93.3-99.999$ & 20 \\
\hline${ }^{243} \mathrm{Cm}$ & $93.3-99.999$ & 0.1 \\
\hline${ }^{244} \mathrm{Cm}$ & 99.3 & 100 \\
\hline${ }^{245} \mathrm{Cm}$ & $98.4-99.998$ & 10 \\
\hline${ }^{246} \mathrm{Cm}$ & $98.0-99.998$ & 40 \\
\hline${ }^{247} \mathrm{Cm}$ & $70 .-90.2$ & 2 \\
\hline${ }^{248} \mathrm{Cm}$ & $95.8-97.0$ & 3 \\
\hline
\end{tabular}

of ${ }^{244} \mathrm{Pu}$ in the ORNL EIEF during the 1970s (designated as FP-33) are stored at ORNL in the form of mixed plutonium isotopes that have ${ }^{244} \mathrm{Pu}$ isotopic purities below $20 \%$. The IAEA initiated a contract with DOE to have the RFNC-VNIIEF separate ${ }^{244} \mathrm{Pu}$ from $5 \mathrm{~g}$ of the FP-33 
$\left(17 \%{ }^{244} \mathrm{Pu}\right)$ material to $99.99 \%$ purity. The first phase of the contract included an initial demonstration test using a 0.5-g sample of FP-33.

To support this project, the RFNC-VNIIEF separations equipment and procedures were upgraded for the preparation of high-purity plutonium chloride, the ionization process, the radiochemical recovery of the material deposited on the collectors or scattered in the machine and the regeneration of the latter (Deron and Vesnovskii 1999). The stages of the technological cycle were modified in an attempt to achieve a steady collection efficiency of 5\% and a recovery of $95 \%$ of the separated isotopes from the collector pockets. The goal of recovering $85 \%$ of the material scattered in the facility was to be achieved by optimizing the reactants used, the design of the source and shielding liner, and the procedures for decontamination.

In the mid-2000s the RFNC-VNIIEF facility was being equipped with a new ion source and electric power source to increase operation temperature of the source so that the separated materials could be used in the form of metals and oxides (Vesnovskii 2004). They were also working to increase the separation efficiencies from 5 to $15-20 \%$ using electromagnetic separation. Efforts to achieve stable characteristics of the mass separator operation include new technologies for producing pure trichlorides as the working substance, 100\% extraction efficiency, and deep purification of accumulated isotopes from collector boxes.

The Russians completed the enrichment demonstration in 2012 using the 0.5-g sample of FP-33 in a two-stage electromagnetic separation (Penkin et al. 2015). The first separation yielded $\sim 10 \mathrm{mg}$ plutonium with $\sim 98.86 \%{ }^{244} \mathrm{Pu}$. The second separation yielded $0.88 \mathrm{mg}$ plutonium with $99.983 \%{ }^{244} \mathrm{Pu}$. The isotopic purity of the final product fell slightly below the target, and the contract expired before the remaining 4.5-g sample could be shipped to Russia. The enriched product, as well as all other materials derived from the FP-33 source material, were returned to the United States where the enriched material will be evaluated for use in making CRMs.

\subsubsection{Idaho Scandinavian Electromagnetic Isotope Enrichment Facility}

Idaho National Laboratory (INL) has a mass separator capable of producing small quantities of high-purity stable isotopes (Carney et al. 2012). In 2008, INL began the revival of the vintage 1970s era instrument shown in Fig. 4. The separator has three major components: a magnet, an ion source coupled to a quadrupole electrostatic ion focusing lens, and a collection/detection system that consists of six Faraday cup detectors, a 2-D spatial profile monitor and a moving wire detector that monitors beam resolution. The magnet is a 5000-G, 59-in.-radius, $90^{\circ}$ sector type manufactured by Scanditronix. Several improvements were made in the ion source designs, source material introduction, ion detection and collection, the vacuum system, and the power supplies. Separation and collection of isotopic species of $\mathrm{Ar}, \mathrm{Kr}, \mathrm{Xe}, \mathrm{Sr}$, and Ba have been tested in the system. Isotopes of high purity (>98 \%) and in quantities in the tens of micrograms per run have been processed through the system. 

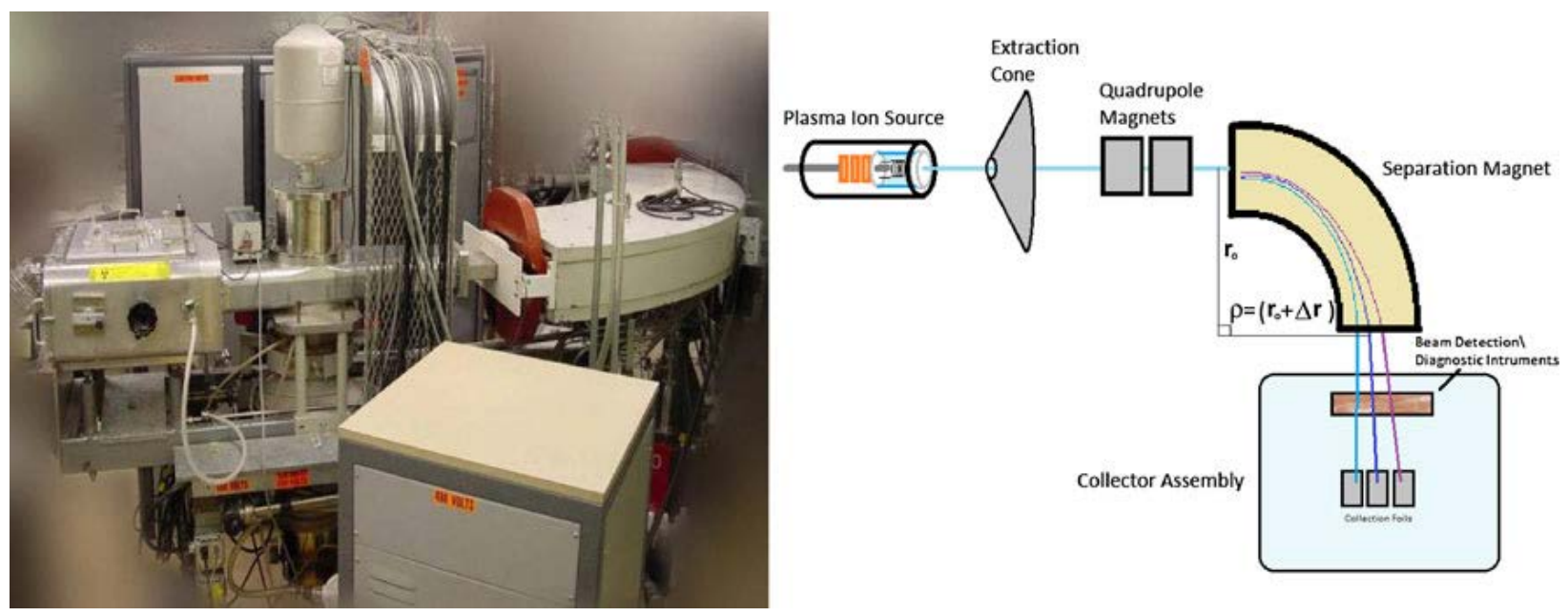

Fig. 4. INL mass separator.

The system has been operated with the objective of producing ${ }^{134} \mathrm{Ba}$ with an isotopic purity of $>99 \%$ in the product for use in IDMS standards. One gram of metallic, natural Ba is typically used as a starting point. Operating the separator for 10-20-h increments with beam currents around 100-200 nA resulted in 5-10 $\mu$ g of ${ }^{134} \mathrm{Ba}$ with purity ranging between 90 and $98 \%$ (Carney et al. 2012; Horkley et al. 2015). Methods evaluated for chemical purification of the separator product included ion exchange and solvent extraction.

INL is also developing a system of similar scale to separate radioactive isotopes (Horley 2016).

\subsubsection{Pacific Northwest National Laboratory Inductively Coupled Plasma Mass Spectrometer}

Pacific Northwest National Laboratory (PNNL) has developed and tested a collector arrangement for a quadrupole inductively coupled plasma mass spectrometer (ICP-MS) for production of nanogram quantities of highly enriched (approximately $99.99 \%$ ) ${ }^{151}$ Eu isotope from a diluted Eu standard with a natural Eu isotopic distribution (Liezers 2015). The test was performed using a model PQ-Excell (VG Elemental Ltd, Winsford, England) quadrupole ICP-MS with no major modifications made to the ICP ion source, plasma-sampling interface, primary ion optics, or quadrupole mass filter. The instrument employed a simultaneous pulse counting/analog multiplier model AF-214 (SGE Inc., Austin, Tex., USA).

Low energy $\left(<10 \mathrm{eV}\right.$ ) ion collection efficiency was observed to be very high. ${ }^{151}$ Eu ion currents of $0.1-0.5 \mathrm{nA}$ were collected on a simple planar foil. Deposition rates were $>10 \mathrm{ng} / \mathrm{h}$. High rejection of adjacent mass isotopes was demonstrated by selectively implanting ${ }^{167} \mathrm{Er}$, then using laser ablation ICP-MS imaging to confirm the absence of any co-implanted ${ }^{166} \mathrm{Er}$ or ${ }^{168} \mathrm{Er}$. The overall ion loss from the solution source to the implant substrate was large, equivalent to $\approx 0.005 \%$ ion transmission efficiency. 


\subsubsection{ORNL Enriched Stable Isotope Production Facility}

Because of a shortage of enriched stable isotopes available from a domestic source, a stable isotope enrichment facility is now under development at ORNL (Egle et al. 2014). The Enriched Stable Isotope Pilot Plant (ESIPP) and associated technology, currently being developed with the support of (the DOE Isotope Program, is a modern high-resolution, high-throughput facility for stable isotope enrichment. The ESIPP includes a small centrifuge cascade, also funded by the DOE Isotope Program.

Original funding was provided by the DOE Isotope Program to develop a prototype EMIS. The prototype (see Figure 5) had the throughput of one-tenth of a calutron. This device features highresolution, large-pole-gap magnetic ion optics, which allow for ion beam currents greater than $1 \mathrm{~mA}$ while maintaining high enrichment by controlling the charge density of the beam. Designed as a production prototype, the device includes removable liners and maintenance features that allow for the recovery of potentially expensive pre-enriched feedstock material from the flight tube and ion source. This feature is of great importance for reducing contamination and maximizing use of the high-value, hard-to-produce feedstock material. The R\&D EMIS has been commissioned, and preliminary isotope separations have been performed with argon and molybdenum. In these initial experiments, ion beam currents up to $10 \mathrm{~mA}$ of argon and $1.5 \mathrm{~mA}$ of molybdenum have been achieved at the collector. The initial enrichment experiments with molybdenum resulted in more than $3 \mathrm{mg}$ of all molybdenum isotopes with a first-pass enrichment of $\sim 98 \%$, with a total average molybdenum ion current at the collector of $0.6 \mathrm{~mA}$.

The prototype EMIS system has been upgraded to $\sim 100 \mathrm{~mA}$ having the capability of producing milligram to tens of grams of enriched stable isotopes (Hart et al. 2015). In the FY2017 President's Budget Request (US DOE 2016), the DOE Isotope Program requested funds to enhance the ESIPP capability to provide up to a $1 \mathrm{~kg} /$ year of production. The enhanced facility will be called the Stable Isotope Production Facility.

As part of this program, ORNL is investigating the combined use of electromagnetic and gas centrifuge isotope separation technologies to provide research quantities (milligram to several kilogram) of enriched stable isotopes. The small, US made centrifuges are intended to provide pre-enriched feed stock to the EMIS device as well as provide a standalone enrichment capability for the DOE Isotope Program. The work at ESIPP is expected to result in the development of advanced, production-ready, ion source technology that will increase the performance and efficiency of future isotope enrichment devices. 


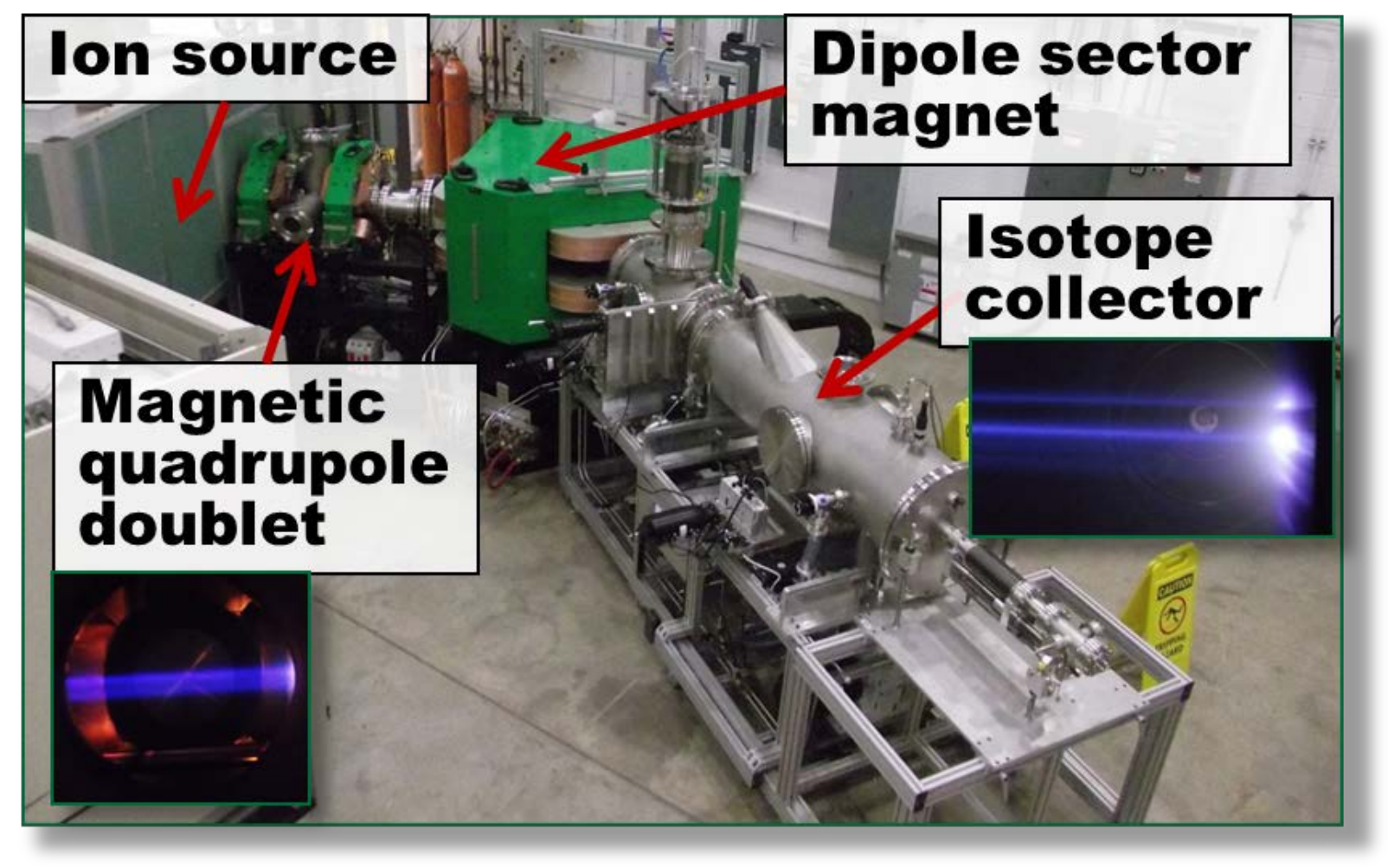

Fig. 5. ORNL EMIS device.

\subsection{IRRADIATION}

Another technique that has been used for actinide enrichment is irradiation (Patton 2014). This technique is applicable only when the desired radioisotope has significantly lower fission cross sections relative to other isotopes, allowing the other isotopes to be "burned out" by fissioning, thus enriching the desired isotope. This technique involves target fabrication, irradiation in a nuclear reactor, processing to remove fission products, and purification of the desired enriched isotope.

A combined EMIS/irradiation technique was successfully demonstrated in the late 1970s to enrich ${ }^{244} \mathrm{Pu}$ in the High Flux Isotope Reactor (HFIR) following initial calutron enrichment. Approximately $150 \mathrm{mg}$ of the ${ }^{244} \mathrm{Pu}$ shown in Table 2 was enriched in the ORNL HFIR by way of burnup from 98.6 to $99.4 \%$ enrichment, yielding higher purity material but with a notable $64 \%$ loss in the mass of ${ }^{244} \mathrm{Pu}$, leaving only $54 \mathrm{mg}$ (Patton 2014).

\subsection{OTHER SEPARATION TECHNOLOGIES}

Several other separation technologies have been considered as alternatives to the electromagnetic separations. These have been primarily considered for the production of enriched uranium but have been demonstrated at least at a proof-of-principle scale for stable isotopes production. They 
include gaseous centrifuge, laser separations such as Atomic Vapor Laser Isotope Separation (AVLIS) and Molecular Laser Isotope Separation (MLIS), Plasma Separation Process (PSP) or ion cyclotron resonance, and physical-chemical techniques.

\subsubsection{Gaseous Centrifuge}

The gas centrifuge isotope separation (GCIS) process is applicable to those elements that will form compounds that have high vapor pressures near room temperature. Enrichment of the gas is accomplished by centrifugation and by internal thermal diffusion due to the counter-current motion of the molecules in the centrifuge. The enriched "product” (lower molecular weight isotopes) and depleted "tails" (higher molecular weight isotopes) are withdrawn, respectively, by scoops located at the ends of the centrifuge. The process is characterized by large throughput but relatively low separation factors (Tracy 1985), requiring groups of centrifuges called "stages” to reach higher isotopic assays. A centrifuge plant is made up of stages to get the required product and tails assays. This set of staged centrifuges makes up a single cascade. It uses identical cascades to increase its throughput; i.e., the cascades are all in parallel. Since centrifuges have only two output streams, they are best suited for separation of elements with two primary isotopes. Multiple isotope elements must undergo repeated runs of the product or tails through the centrifuges, in a batch-type process, to separate the middle molecular weight isotopes. Also, to gain the highest isotopic purity, the compound should contain no more than one other monoisotopic element. The compounds most often used are fluorides. The gas centrifuge is operated under a vacuum, and this places an additional constraint on usable compounds; the compound must be sufficiently massive to remain in the centrifuge during operation.

In the mid-1970s, the former USSR began to develop the centrifugal separation process for stable isotope production. By 1990, the volume of centrifuge production reached 50 to $60 \%$ of the total Russian stable isotopes production, but the electromagnetic separation process remained the unique method used for about two-thirds of the chemical elements which have no stable volatile compounds (Pokidychev and Pokicycheva 1999). Stable isotopes produced by this method include sulfur, iron, noble gases, molybdenum, tungsten, tin, lead, cadmium, zinc and nickel. The RFNC-VNIIEF facility is equipped with high-speed centrifuges for production of extremely pure stable isotopes (Vesnovskii 2003).

\subsubsection{Laser and Plasma Separations}

In the early 1970s, DOE launched the Advanced Isotope Separation (AIS) program to develop and test alternative advanced methods of enriching uranium at lower cost. The methods investigated included MLIS, AVLIS, and PSP. All three programs were successfully demonstrated in laboratory-scale, pre-prototype hardware tests in the United States (Tracy 1989).

The PSP is based on the ion cyclotron resonance of a charged particle in a uniform magnetic field. In the PSP the atoms of the desired element or compound are vaporized, converted to ions, 
constrained and directed by a solenoidal magnetic field, selectively energized by an applied electric field at the ion cyclotron frequency of the desired isotope, and collected by plates spaced to intercept the enlarged orbits of the desired isotope. The remaining isotopes pass between the collection plates and are collected at the tails plates (Tracy and Terry 1985).

In the AVLIS process, the atoms of the desired isotope are ionized by lasers in a multistep process and collected on plates. MLIS uses an infrared laser directed at $\mathrm{UF}_{6}$, exciting molecules that contain a ${ }^{235} \mathrm{U}$ atom. A second laser frees a fluorine atom, leaving uranium pentafluoride which then precipitates out of the gas.

Both the AVLIS and PSP are potentially applicable to all the elements that have been separated in the calutrons. The processes are specific to a single isotope per separation (Tracy and Terry 1985). The AIS selected AVLIS over PSP as the uranium enrichment method of the future, and the AIS pre-prototype PSP machine was transferred to Oak Ridge for use in production of stable isotopes (Tracy 1989). The equipment was operated by Theragenics ${ }^{\mathrm{TM}}$ from 2002 until it was shut down for business reasons in 2006. Twelve stable isotopes were enriched at Theragenics, including ${ }^{60} \mathrm{Ni},{ }^{62} \mathrm{Ni},{ }^{70} \mathrm{Zn},{ }^{92} \mathrm{Mo},{ }^{98} \mathrm{Mo},{ }^{100} \mathrm{Mo},{ }^{102} \mathrm{Pd},{ }^{157} \mathrm{Gd},{ }^{160} \mathrm{Gd},{ }^{164} \mathrm{Dy},{ }^{167} \mathrm{Eu}$, and

${ }^{170} \mathrm{Eu}$ (Bigelow 2005). AVLIS was further developed for enrichment of uranium and plutonium. The plutonium effort was dropped when the demand for weapons grade plutonium decreased.

Development of laser and PSP separations technologies for stable isotopes never advanced beyond the research stage in the former Soviet Union when state financing for the programs was terminated in the early 1990s. Private sector development continued, and by 1999 up to 30-40\% of the middle and heavy isotopes being enriched in Russia used laser technology (Pokidychev and Pokicycheva 1999). No recent information was found in the open literature.

\subsubsection{Physical-chemical Separations}

The French CHEMEX process was developed and demonstrated to pilot-plant stage to enrich uranium (Dugarin 1990), but it was abandoned as laser enrichment technologies became available. It exploited a very slight difference in the two isotopes' propensity to change valency in oxidation/reduction, utilizing immiscible aqueous and organic phases. An ion-exchange process was also developed by the Asahi Chemical Company in Japan which applies similar chemistry but effects separation on a proprietary resin ion-exchange column (Seko 1990).

A photochemical process was developed and used for separation of mercury isotopes at a capacity needed to meet most of the mercury isotope demands of Russia (Pokidychev and Pokicycheva 1999). The production of some light isotopes, in particular ${ }^{18} \mathrm{O}$, has also been met using the physical-chemical methods in Russia (Pokidychev and Pokicycheva 1999). 


\section{POTENTIAL TECHNOLOGIES FOR FUTURE ACTINIDE ENRICHMENT}

\subsection{INDIVIDUAL ENRICHMENT TECHNOLOGIES}

EMIS is the only technology that has been reported to have been used in the past to enrich multigram quantities of actinides other than uranium, and irradiation technology has been used to produce small quantities of a limited number of isotopes. Other enrichment technologies have only been reportedly used for production of stable isotopes as described in Sect. 2.

All of the technologies discussed in this report could be considered for implementation of future actinide enrichment capabilities. The attributes of these potential enrichment processes are listed in Table 4 (Egle 2014; Tracy 1991; Patton 2014).

Table 4. Comparison of enrichment technologies

\begin{tabular}{|c|c|c|c|c|c|}
\hline & $\begin{array}{c}\text { Typical } \\
\text { Quantities }\end{array}$ & $\begin{array}{c}\text { Enrichment } \\
\text { per pass }\end{array}$ & $\begin{array}{c}\text { Isotope } \\
\text { Collection }\end{array}$ & $\begin{array}{l}\text { Separation } \\
\text { Medium }\end{array}$ & $\begin{array}{c}\text { Research } \\
\text { Required for } \\
\text { New } \\
\text { Isotopes }\end{array}$ \\
\hline $\begin{array}{l}\text { Electromagnetic Isotope } \\
\text { Separation (EMIS) }\end{array}$ & $\mathrm{mg}$ to $\mathrm{g}$ & High & $\begin{array}{l}\text { All } \\
\text { simultaneous }\end{array}$ & Ions & Low \\
\hline $\begin{array}{l}\text { Gas Centrifuge Isotope } \\
\text { Separation (GCIS) }\end{array}$ & $\mathrm{kg}$ & Low & End isotopes & Gas & Medium \\
\hline Gas Diffusion & kg & Very low & End isotopes & Gas & High \\
\hline $\begin{array}{l}\text { Plasma Separation } \\
\text { Process (PSP) }\end{array}$ & $\mathrm{kg}$ & Moderate & Single targeted & Ions & Medium \\
\hline $\begin{array}{l}\text { Atomic Vapor Laser } \\
\text { Isotope Separation }\end{array}$ & $\mathrm{kg}$ & Moderate & Single targeted & Vapor-ions & High \\
\hline $\begin{array}{l}\text { Chemical and physical } \\
\text { processes }\end{array}$ & $\mathrm{kg}$ & Varies & Varies & Varies & High \\
\hline Irradiation & $\mathrm{mg}$ to $\mathrm{g}$ & Low & End isotopes & Varies & Low \\
\hline
\end{tabular}

EMIS technology is the most versatile known means of separating isotopes (Love 1973). It has been used to enrich most the elements on the periodic table. It has a high first-pass enrichment capability ( $10 \%$ natural abundance to $99 \%$ enrichment in one pass), can enrich all isotopes of an element simultaneously, and has a throughput on the order of milligrams per hour. Other enrichment methods provide larger throughput, but they require multi-staging to obtain high enrichments and are either isotope selective or alter the feed abundance to enhance either the heaviest or lightest isotope (Tracy and Aaron 1993).

GCIS has a throughput on the order of grams per hour, depending on the size, which is substantially higher than EMIS; however, it is limited to elements that have volatile chemical 
analogs, has lower single-pass enrichments, and is limited in its ability to target more than one isotope of an element during an enrichment campaign.

The AVLIS and PSP are applicable to a wider range of isotopes than the gaseous centrifuge. They are, however, specific to a single isotope per separation (Tracy 1985). The PSP is isotope selective, has a low enrichment factor, and is particularly adaptable to the isotopic enrichment of the metal elements. The enrichment factor for the PSP is approximately one-tenth that of the calutron, but it has throughput capabilities of $\sim 1000$ production calutrons.

Irradiation is applicable only when the desired radioisotope has significantly lower fission cross sections relative to other isotopes, allowing the other isotopes to be "burned out" by fissioning, thus enriching the desired isotope. Patton et al. $(2014,2016)$ evaluated enrichment by irradiation in the ORNL HFIR and concluded that enrichment by irradiation could be successful in only a limited number of special cases. For example, Mark-18A material containing $5 \%{ }^{244} \mathrm{Pu}$ could be enriched to $13 \%$ with 18 irradiation cycles, and Mark-42 material containing $\sim 50 \%{ }^{242} \mathrm{Pu}$ could be enriched to $~ 90 \%$ with 18 irradiation cycles. Engle et al. (2013) calculated that radioisotopic purities of ${ }^{242} \mathrm{Pu}$ in excess of $99.5 \%$ could be achieved by irradiating plutonium materials with an initial ${ }^{242} \mathrm{Pu}$ concentration of $95 \%$.

\subsection{COMBINED ENRICHMENT TECHNOLOGIES}

Although the EMIS process is the most versatile of the enrichment technologies, it is ion-current limited. To obtain gram quantities of isotopes of low natural abundance, it is desirable to increase the concentration of that isotope to approximately 2 at.\% in the calutron feed material. Methods to perform this isotopic pre-enrichment were investigated for stable isotope production with the goal of assessing whether large quantities of highly enriched material could be produced at costs substantially below calutron costs (Tracy 1985). The study looked at the potential for combining EMIS and AVLIS, GCIS, and PSP technologies. The cost effectiveness of these processes was compared assuming the significant part of the cost associated with enriched isotopes is directly related to the energy consumed during the separation. The cost effectiveness of the technologies was evaluated based on the energy consumed to produce one gram of enriched ${ }^{50} \mathrm{~V}$. The energy requirement for each type of separator is shown in Table 5.

Table 5. Cost effectiveness of isotopes enrichment processes

\begin{tabular}{|c|c|c|}
\hline Separator Technology & $\begin{array}{c}\text { Energy requirement to produce 1 g } \\
\text { of }{ }^{\mathbf{5 0}} \mathbf{V} \text { enriched to } \mathbf{1 0} \text { at. } \% .\end{array}$ & Enrichment (at. \%) \\
\hline Calutron & $\sim 4.4 \times 10^{6} \mathrm{MJ}$ & 36 (single pass) \\
\hline AVLIS & $18-138 \mathrm{MJ}$ & 10 \\
\hline GCIS & $\sim 36 \mathrm{MJ}$ & 10 \\
\hline PSP & $<360 \mathrm{MJ}$ & 10 \\
\hline
\end{tabular}


Assuming the ${ }^{50} \mathrm{~V}$ was pre-enriched by the most energy efficient of these alternative processes and then the product was used as feed for calutrons, a final product of $>95$ at. $\%{ }^{50} \mathrm{~V}$ was estimated to be produced at about 3\% of the cost of enrichment through the calutrons alone. The conclusion of this study was that pre-enrichment of calutron feed by one, or a combination, of the alternative processes could result in a cost-effective operating approach for providing enriched stable isotopes. The PSP was also considered to be extremely beneficial for producing some calutron feed material, especially for those isotopes having low natural abundance (Tracy 1991) and compatible with the PSP.

More recently, ORNL has investigated the combined use of electromagnetic and gas centrifuge isotope separation technologies to provide research quantities (milligram to several kilogram) of enriched stable isotopes. It is estimated that the use of a combined gas centrifuge and electromagnetic separation process would require $<30 \%$ of the capacity that an EMIS system alone would require to produce $98 \%$ enriched ${ }^{98}$ Mo and ${ }^{100}$ Mo (Egle 2014).

A combined EMIS/irradiation technique was successfully demonstrated in the late 1970s to enrich ${ }^{244} \mathrm{Pu}$ in HFIR following initial calutron enrichment (Patton 2014). Recent modeling of the process indicates that one irradiation cycle in the HFIR flux trap could increase the enrichment of existing material in the ORNL inventory from $98.8 \%$ to $99.1 \%$ with only $2 \%{ }^{244} \mathrm{Pu}$ loss. The technique may be useful in support of a future EMIS device to pre-enrich actinide material to increase throughput and to post-enrich material to reduce product losses of a second pass in an EMIS system. 



\section{ACTINIDE ENRICHMENT REQUIREMENTS}

The 15 actinide radioisotopes have atomic numbers ranging from 89 to 103 (actinium through lawrencium). With the exception of ${ }^{232} \mathrm{Th},{ }^{235} \mathrm{U}$, and ${ }^{238} \mathrm{U}$, which occur naturally in substantial quantities, the actinide radioisotopes are produced synthetically by irradiation in nuclear reactors, generally with low isotopic purity. The isotopes of interest then must be enriched to obtain the purity required for user applications such as national security, nuclear nonproliferation, and basic research programs.

A list of user needs for actinide radioisotopes was obtained through a variety of sources, including open literature technical documents and canvasing users with science and technology needs. The list focuses on the desires for high-purity actinide materials for the nuclear forensics and research programs in the United States. They do not reflect demand forecasts based on presently available materials.

The existing inventories of enriched actinides and/or the existing production capabilities for enriched actinides were evaluated to determine if they could meet anticipated user demand. The needs that could not be met through existing inventories and/or existing production capabilities were used as the basis of this actinide enrichment requirements evaluation. A list of uses of enriched actinide radioisotopes is given in Table 6, and a list of the enrichment projections is given in Table 7.

Both ${ }^{242} \mathrm{Pu}$ and ${ }^{244} \mathrm{Pu}$ can be used as nuclear forensic tracers. As the world continues to run nuclear power plants and recycled fuels, the amount of ${ }^{242} \mathrm{Pu}$ in the environment will increase, thus decreasing the suitability of ${ }^{242} \mathrm{Pu}$ for nuclear forensics. Plutonium-244, however, is not produced in appreciable quantities in standard power reactor fuel; therefore, the demand for the very limited existing supply of enriched ${ }^{244} \mathrm{Pu}$ is predicted to increase in the future.

Enriched ${ }^{244} \mathrm{Pu}$ material is also needed as target material for heavy ion bombardment for studies of transactinide elements, which are used in the production and discovery of the super heavy elements. In December 1998, for example, a team of scientists from Lawrence Livermore National Laboratory collaborated with Russian scientists at the Joint Institute for Nuclear Research in Dubna, Russia, on the discovery of element 114 using a heavy ion cyclotron to bombard a film of ${ }^{244} \mathrm{Pu}$ with ${ }^{48} \mathrm{Ca}$ ions for 40 days (a discovery that was recognized by Popular Science as one of the year's 100 greatest achievements in science and technology).

In addition, ${ }^{244} \mathrm{Pu}$ has a half-life that is more than 200 times longer than any other plutonium isotope and a low specific activity (1.9E-5 Ci/g), making it extremely useful in studies that attempt to understand the fundamental thermodynamics of plutonium in either the solution or solid state. Plutonium-244 is also the prime isotope for plutonium tracing (e.g., in the marine environment). 
Table 6. Beneficial uses of enriched actinide radioisotopes

\begin{tabular}{|c|c|l|}
\hline Enriched actinide & Use & \multicolumn{1}{|c|}{ Users } \\
\hline${ }^{236} \mathrm{~Np}$ & Nuclear forensics & $\begin{array}{l}\text { Department of Homeland Security } \\
\text { Department of Energy } \\
\text { Defense Threat Reduction Agency } \\
\text { Intelligence Community } \\
\text { International Atomic Energy Agency }\end{array}$ \\
\hline${ }^{242} \mathrm{Pu}$ & Plutonium research & $\begin{array}{l}\text { Department of Energy National Nuclear Security } \\
\text { Administration }\end{array}$ \\
\hline${ }^{242} \mathrm{Pu}$ & Super heavy element (SHE) & Department of Energy SHE Research Community \\
\hline${ }^{244} \mathrm{Pu}$ & SHE research/nuclear forensics & $\begin{array}{l}\text { Department of Homeland Security } \\
\text { Department of State } \\
\text { Defense Threat Reduction Agency } \\
\text { Intelligence Community } \\
\text { International Atomic Energy Agency } \\
\text { Department of Energy SHE Research Community }\end{array}$ \\
\hline${ }^{244} \mathrm{Cm}$ & SHE research & Department of Energy SHE Research Community \\
\hline${ }^{248} \mathrm{Cm}$ & SHE research & Department of Energy SHE Research Community \\
\hline${ }^{251} \mathrm{Cf}$ & SHE research & Department of Energy SHE Research Community \\
\hline
\end{tabular}


Table 7. Actinide enrichment projections

\begin{tabular}{|c|c|c|c|}
\hline Enriched Actinide & Use & Isotopic Purity Desired & $\begin{array}{c}\text { Maximum Quantity Desired } \\
\text { Over 5 Year Period }\end{array}$ \\
\hline${ }^{236} \mathrm{~Np}$ & MS Tracer & $99.99 \%$ & $1-2 \mathrm{mg}$ \\
\hline${ }^{242} \mathrm{Pu}$ & Plutonium Research & $99 \%$ & TBD \\
\hline${ }^{242} \mathrm{Pu}$ & SHE Research & $99.9 \%$ & $200 \mathrm{mg}$ \\
\hline${ }^{244} \mathrm{Pu}$ & SHE Research & $99.9 \%$ & $1,000 \mathrm{mg}$ \\
\hline${ }^{244} \mathrm{Pu}$ & MS Tracer and Standards & $99.99 \%$ & $2-5 \mathrm{gram}$ \\
\hline${ }^{244} \mathrm{Cm}$ & SHE Research & $99.9 \%$ & $220-500 \mathrm{mg}$ \\
\hline${ }^{248} \mathrm{Cm}$ & SHE Research & $99.9 \%$ & $650 \mathrm{mg}$ \\
\hline${ }^{251} \mathrm{Cf}$ & SHE Research & $99.9 \%$ & $650 \mathrm{mg}$ \\
\hline
\end{tabular}


Like ${ }^{244} \mathrm{Pu},{ }^{242} \mathrm{Pu}$ has a long half live and a specific activity $(0.004 \mathrm{Ci} / \mathrm{g})$, much lower than other common isotopes of plutonium $\left({ }^{239} \mathrm{Pu},{ }^{240} \mathrm{Pu}\right.$ and $\left.{ }^{241} \mathrm{Pu}\right)$. Therefore, highly enriched ${ }^{242} \mathrm{Pu}$ can be handled in a facility with fewer safety requirements. It is available in larger quantities than ${ }^{244} \mathrm{Pu}$. The advantages of using enriched ${ }^{242} \mathrm{Pu}$ for $\mathrm{R} \& \mathrm{D}$ activities are described in the Integrated Plutonium Science and Research Strategy (LANL/LLNL 2015).

An example of the quantities of ${ }^{242} \mathrm{Pu}$ that can be handled in a DOE radiological facility (US DOE 1997) is shown in Fig. 6 as a function of enrichment. It shows that $>500 \mathrm{~g}$ of highly enriched ${ }^{242} \mathrm{Pu}$ could be in a DOE radiological facility at one time. It should be noted that the quantities in Fig. 6 were calculated for an existing ${ }^{242} \mathrm{Pu}$ material with a known isotopic composition because the quantities that can be handled in a radiological facility are significantly dependent on the specific isotopic impurities in the sample.

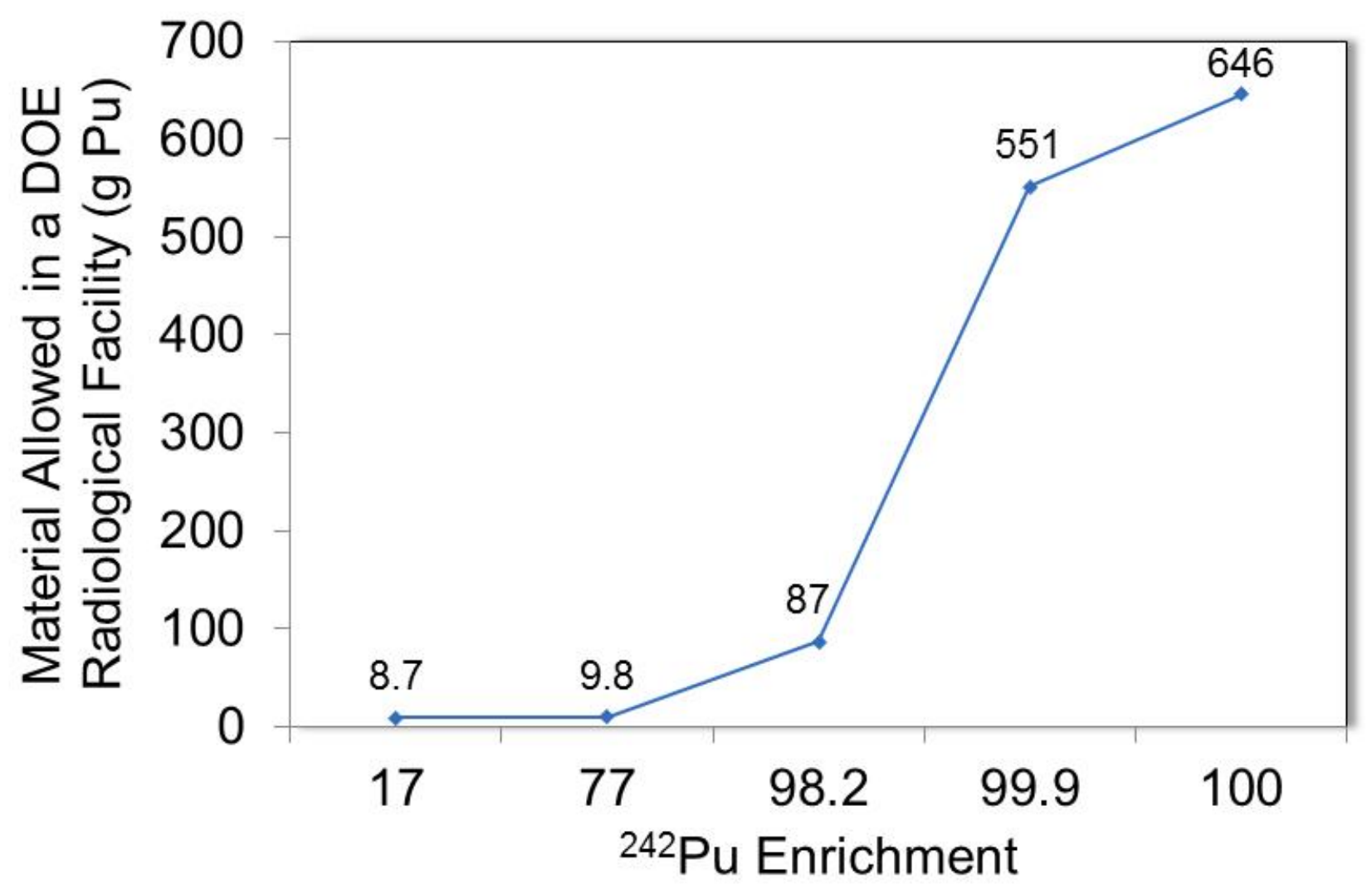

Fig. 6. Amount of ${ }^{242} \mathrm{Pu}$ allowed in a DOE radiological facility as a function of enrichment.

Neptunium-236 is of interest for use as an IDMS tracer for the radiochemical analysis of ${ }^{237} \mathrm{~Np}$. Neptunium-237 is significant in a number of fields of research such as nuclear forensics, environmental analysis, and the nuclear fuel cycle. Although various radioactive tracers have been used, including ${ }^{235} \mathrm{~Np},{ }^{239} \mathrm{~Np}$ and ${ }^{236} \mathrm{Pu}$, none have been found to be satisfactory. Neptunium-236 is a potential candidate as a neptunium yield tracer, as its $1.55 \times 10^{5}$-year radioactive half-life allows it to be used for both radiometric and mass spectrometric 
measurements. Neptunium-236 synthesis is under investigation using such techniques as bombardment of natural uranium with protons (Jerome et al. 2014; Larijani et al. 2015). Any of the synthesis techniques under development will require enrichment of the product before it can be used.

Long-lived actinide materials, including ${ }^{244} \mathrm{Cm},{ }^{248} \mathrm{Cm},{ }^{242} \mathrm{Pu}$, and ${ }^{244} \mathrm{Pu}$, are used in super heavy element research to connect the proposed "hot fusion island of stability" to the nuclear mainland, to study decay properties including fission probabilities, and to investigate reaction mechanisms (Texas A\&M 2013). Californium-251, ${ }^{244} \mathrm{Cm}$, and ${ }^{248} \mathrm{Cm}$ are used in super-heavy element discovery research (Texas A\&M 2013; Roberto 2015). Californium-251 was used in the recent discovery of super heavy element 118 , and it is being used in super-heavy element experiments for the synthesis of element 118. It is being considered for experimental studies to discover elements beyond element 118, including elements 119, 120, and beyond. Curium-248 is also a very desirable research isotope for new element discovery because of its high neutron-to-proton ratio and is the isotope of choice for curium chemistry studies because of its long half-life $\left(3.4 \times 10^{5}\right.$ years $)$ and relatively low specific activity $(0.00424 \mathrm{Ci} / \mathrm{g})$. It has been identified for use in discovery research for element 120. Curium 248 is also used as the primary feed stock in the production of ${ }^{252} \mathrm{Cf}$ and the co-production of ${ }^{249} \mathrm{Bk}$ that was used in the discovery and verification of element 117, which was recently officially named Tennessine. 



\section{ENRICHMENT TECHNOLOGY GAPS}

\subsection{CAPABILITY REQUIREMENTS}

The user projections identified in Sect. 4 indicate that actinide enrichment capabilities are needed to produce milligram-to-gram quantities of ${ }^{236} \mathrm{~Np},{ }^{242} \mathrm{Pu},{ }^{244} \mathrm{Pu},{ }^{251} \mathrm{Cf},{ }^{244} \mathrm{Cm}$, and ${ }^{248} \mathrm{Cm}$ at purity levels ranging from 99\% to 99.99\%. Review of existing enrichment capabilities in Sect. 2 indicate that no domestic facility exists that can meet these requirements. As shown in Fig. 7, the existing enrichment facilities at PNNL and INL are producing nanogram-to-microgram quantities of highly enriched actinides, well below the future requirements of milligram-to-gram quantities.

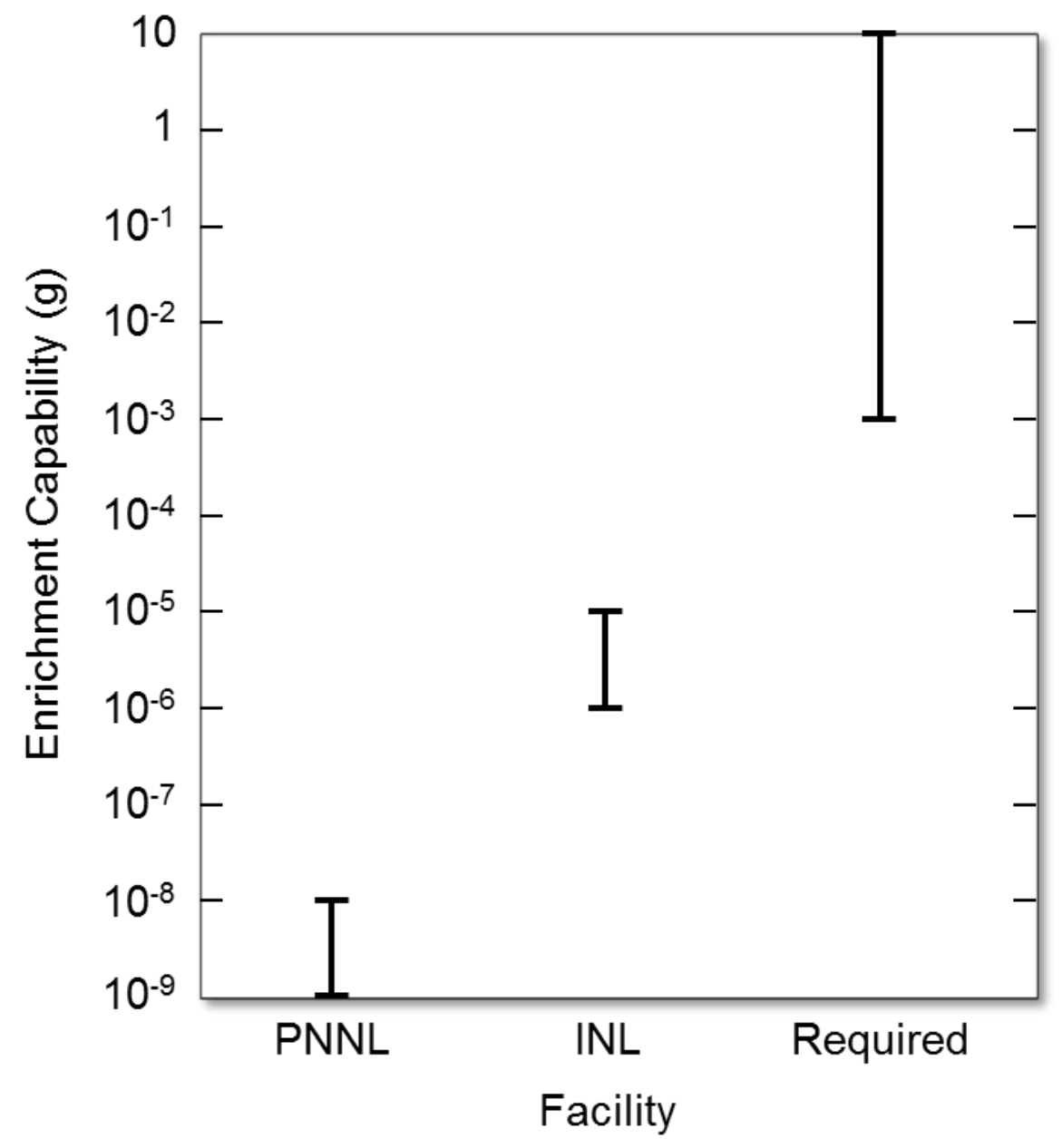

Fig. 7. Existing enrichment capabilities compared to future requirements.

This indicates that new capabilities will be needed to meet enrichment requirements for actinides at high-purity levels. These new capabilities should be designed as a minimum to meet the demands for ${ }^{236} \mathrm{~Np},{ }^{242} \mathrm{Pu},{ }^{244} \mathrm{Pu},{ }^{244} \mathrm{Cm},{ }^{248} \mathrm{Cm}$, and ${ }^{251} \mathrm{Cf}$, as described in Sect. 4 and have the flexibility to be adapted to meet future requirements for larger quantities of these materials 
and/or other actinides which may be needed in the future to meet the demands for unique materials of user communities and a new generation of researchers.

The initial preliminary technology assessment in Sect. 3 indicates that the EMIS technology is the only technology that has been demonstrated for enrichment of these actinides and is the most flexible technology for meeting additional actinide demands in the future. Therefore, it is the most viable technology for reestablishing actinide enrichment capabilities in the United States. Recent advances in the enrichment technology that are being investigated at prototype scales for production of very small quantities of materials, primarily stable isotopes, should be considered the next generation actinide EMIS equipment to increase the efficiency and reduce the cost of production of enriched actinides compared to the World War II era systems.

The estimated EMIS feed rates needed to meet the enrichment requirements summarized in Sect. 4 are listed in Table 8 . Domestic sources of feed stocks that could be considered for enrichment to meet these requirements are also listed in Table 8.

\subsection{SHIELDING CONSIDERATIONS}

Preliminary shielding requirements for the production of each radioisotope have been estimated in Table 8. They assume that the feedstock materials will be processed to separate the radionuclide of interest from the feedstock material prior to entering the EMIS facility. Equipment to enrich ${ }^{242} \mathrm{Pu},{ }^{244} \mathrm{Pu}$, and ${ }^{236} \mathrm{~Np}$ should not require shielding.

The shielding required to enrich ${ }^{251} \mathrm{Cf}$ has been estimated assuming decayed ${ }^{252} \mathrm{Cf}$ sources in storage at ORNL are used as feedstock, i.e., $49.9 \mathrm{wt} \%{ }^{249} \mathrm{Cf}, 13.7 \mathrm{wt} \%{ }^{250} \mathrm{Cf}$, and $26.4 \mathrm{wt} \%{ }^{251} \mathrm{Cf}$. An unshielded point source of $100 \mathrm{mg}$ with this composition is estimated to have a dose rate of $1.6 \mathrm{R} / \mathrm{h}$ at a distance of $1 \mathrm{ft}$.

The shielding required to enrich ${ }^{248} \mathrm{Cm}$ has been estimated assuming decayed ${ }^{252} \mathrm{Cf}$ sources in storage at ORNL are used as feedstock, i.e., $95.03 \mathrm{wt} \%{ }^{248} \mathrm{Cm}, 4.96 \mathrm{wt} \%{ }^{246} \mathrm{Cm}, 0.0065 \mathrm{wt} \%$ ${ }^{244} \mathrm{Cm}$, and $0.00002 \mathrm{wt} \%{ }^{252} \mathrm{Cf}$. An unshielded point source of $1 \mu \mathrm{g}$ with this composition is estimated to have a dose rate of 2.11E-7 R/h at a distance of $1 \mathrm{ft}$. A 1-mg source had a dose rate of $2.11 \mathrm{E}-4 \mathrm{R} / \mathrm{h}$, and a $10-\mathrm{mg}$ source had a dose rate of $2.11 \mathrm{E}-3 \mathrm{R} / \mathrm{h}$.

\subsection{PRE- AND POST ENRICHMENT REQUIREMENTS}

Pre-enrichment and/or post-enrichment technologies, such as irradiation, as discussed in Sect. 3.2, should be considered for future applications to increase the throughput, reduce losses of material, and/or reduce operational costs of the basic EMIS enrichment system. In particular, they should be considered for products requiring ultra-high purity where more than one pass through the EMIS would be required to meet the user enrichment specification.. 
Table 8. Preliminary enrichment requirements

\begin{tabular}{|c|c|c|c|c|c|c|c|}
\hline $\begin{array}{l}\text { Enriched } \\
\text { Isotope } \\
\text { Needed }\end{array}$ & $\begin{array}{l}\text { Half-Life } \\
\text { (years) }\end{array}$ & $\begin{array}{l}\text { Desired } \\
\text { Product } \\
\text { Isotopic } \\
\text { Purity }\end{array}$ & $\begin{array}{c}\text { Potential Feed Stock for } \\
\text { Enrichment }\end{array}$ & $\begin{array}{l}\text { Amount of } \\
\text { Potential Feed } \\
\text { Stock (g) }\end{array}$ & $\begin{array}{l}\text { Potential Feed } \\
\text { Stock Purity }\end{array}$ & $\begin{array}{l}\text { Potential } \\
\text { EMIS Feed } \\
\text { Rate }\end{array}$ & $\begin{array}{l}\text { Shielding } \\
\text { Required }\end{array}$ \\
\hline${ }^{236} \mathrm{~Np}$ & 155,000 & $99.99 \%$ & $\begin{array}{l}\text { No material presently available. } \\
\text { Production pathways under } \\
\text { development }\end{array}$ & 0 & $\sim 50 \%$ & $\mu \mathrm{g} / \mathrm{h}$ & No \\
\hline${ }^{244} \mathrm{Pu}$ & $80,000,000$ & $99.99 \%$ & $\begin{array}{l}\text { Mk-18A Targets in storage at } \\
\text { Savannah River Site }\end{array}$ & 450 & $5-17 \%$ & $50 \mathrm{mg} / \mathrm{h}$ & No \\
\hline${ }^{242} \mathrm{Pu}$ & 375,000 & $99.9 \%$ & $\begin{array}{l}\text { Mk-42 materials in storage at } \\
\text { ORNL and other previously } \\
\text { enriched Pu-242 }\end{array}$ & 1500 & $65-95 \%$ & $50 \mathrm{mg} / \mathrm{h}$ & No \\
\hline${ }^{244} \mathrm{Cm}$ & 18 & $99.9 \%$ & Inventory at ORNL & 250 & $54-85$ & $5 \mathrm{mg} / \mathrm{h}$ & Yes \\
\hline${ }^{248} \mathrm{Cm}$ & 350,000 & $99.9 \%$ & $\begin{array}{l}\text { Decayed Cf-252 sources in } \\
\text { storage at ORNL }\end{array}$ & $\begin{array}{l}0.090 \text { separated, } \\
2 \text { unseparated }\end{array}$ & $80-88 \%$ & $5 \mathrm{mg} / \mathrm{h}$ & Yes \\
\hline${ }^{251} \mathrm{Cf}$ & 900 & $99.9 \%$ & $\begin{array}{l}\text { Decayed Cf-252 sources in } \\
\text { storage at ORNL }\end{array}$ & 0.47 & $31 \%$ & $5 \mathrm{mg} / \mathrm{h}$ & Yes \\
\hline
\end{tabular}




\subsection{SUPPORT SYSTEMS}

As shown in Fig. 8, a significant support system is required to implement an EMIS enrichment device (Egle 2014). The design of these auxiliary support systems is extremely important for production of highly enriched actinides where the quantity of both feedstock and product are likely to be limited and are highly valued. Adding to the complexity of the system design, the operations must be accomplished in a radioactive environment

\subsection{ORNL ACTINIDE ENRICHMENT STUDY}

In 2016, ORNL initiated a study to develop an engineering concept for an EMIS system that could meet the enrichment gaps defined in this report as a step toward reestablishing U.S. actinide enrichment capabilities. The results of this study will not be available until late 2017 (Romano 2016).

\subsection{CBNM ACTINIDE ENRICHMENT STUDY}

In 1985, a design study was undertaken by the Central Bureau for Nuclear Measurements (CBNM) for a medium current EMIS system that could meet the needs of the European community for thorium, uranium, and plutonium in (Berg et al. 1985). The study indicated that the annual need in 1985 was milligram-to-gram quantities ranging in purity levels of 8099.998\% for these enriched isotopes. It was determined that it was more economical to buy these materials from the US and Russian sources, and pursuit of the system was discontinued. Although the system was never constructed and EMIS technology has advanced considerably since 1985, the concepts used for the design of the facility, particularly the auxiliary equipment, are worth considering as a starting point for design of a system to reestablish US actinide enrichment capabilities. The system design is summarized below.

The geometrical arrangement of the proposed separator is shown in Fig. 9. Alpha containment for the system is provided by five glove boxes (A, B, C, D, and E). The source box (A) is used for the assembly and disassembly of the ion source (\#1). Directly coupled to glove box (A) is a small box (B) which is used for removing the straight liner (\#6) between the ion source box (A) and the magnet chamber (\#7). The small box (D) is used for removing the straight liner (\#10) between the magnet chamber (\#7) and the collector chamber (\#13) and is again directly coupled to the collector glove box (E). The collector glove box (E) is equipped with a small carriage for transport of the collector. Glove box (C) is used for disassembly of the liner (\#8) in the magnet chamber (\#7). It is directly connected to a rectangular opening (\#15) in the magnet chamber. Because of the pyrophoricity of the metallic actinide materials handled in the separator, the atmosphere in the glove boxes must be inert. For this purpose, the glove boxes are connected to an argon (or nitrogen) circulation and purification system. They are further provided with "plastic bagging” exits (\#16) in their stainless-steel bottom plates. 


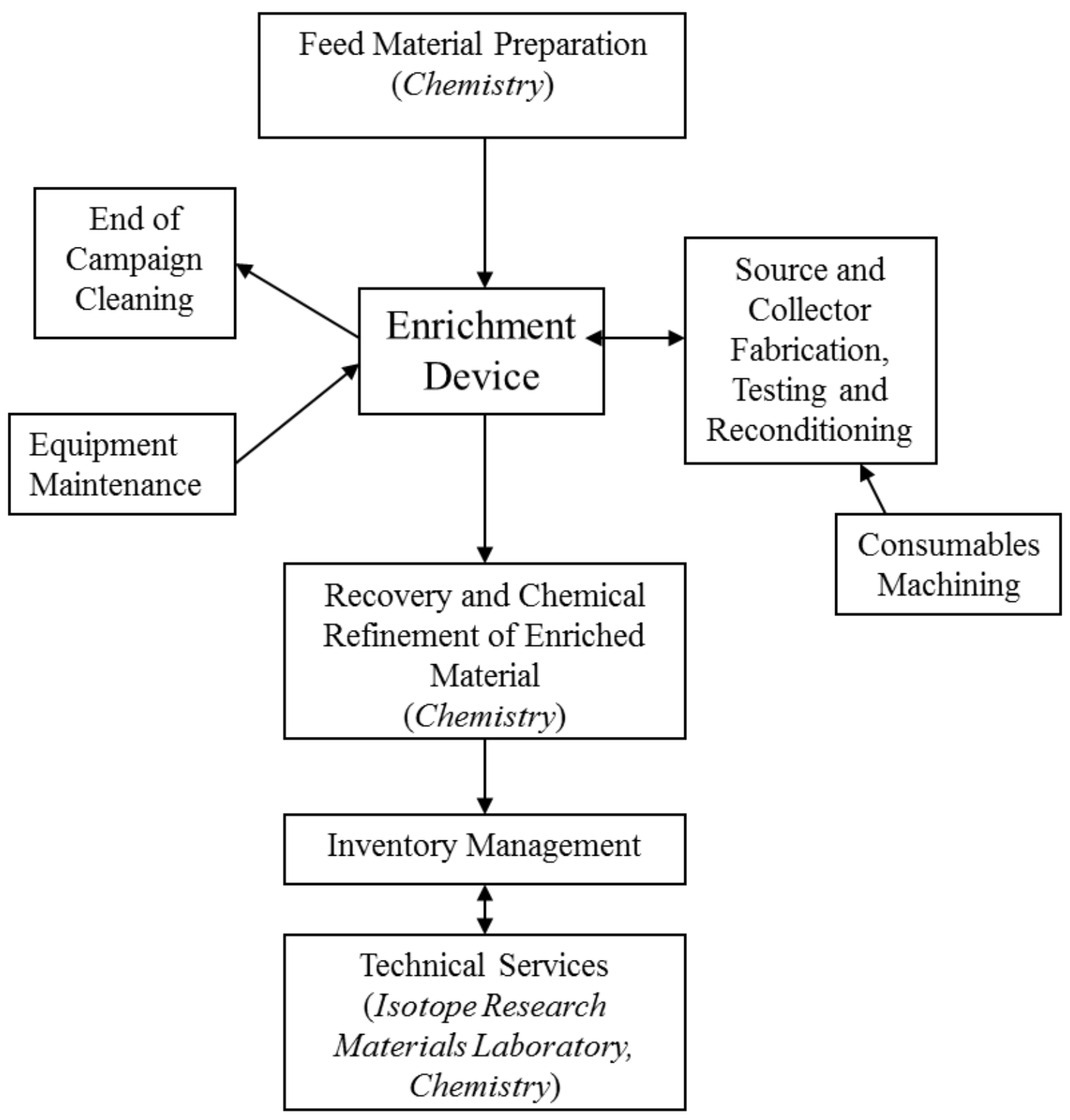

Fig. 8. EMIS enrichment process support requirements.

The glove boxes (A) to (E) are only used for assembly and disassembly of the ion source, the collector, and the liner system. These glove boxes will not contain any cleaning baths to avoid corrosion of the sensitive parts of the separator by aggressive vapors circulated by the argon ventilation system. All other necessary operations such as cleaning of the separator parts and processing of feed material and separated material are carried out in an associated but separate actinide handling facility as shown in Fig. 10.

On the left are the operations related to the recovery and processing of the non-separated actinide material. This includes all the material that was deposited on the inner parts of the separator but 


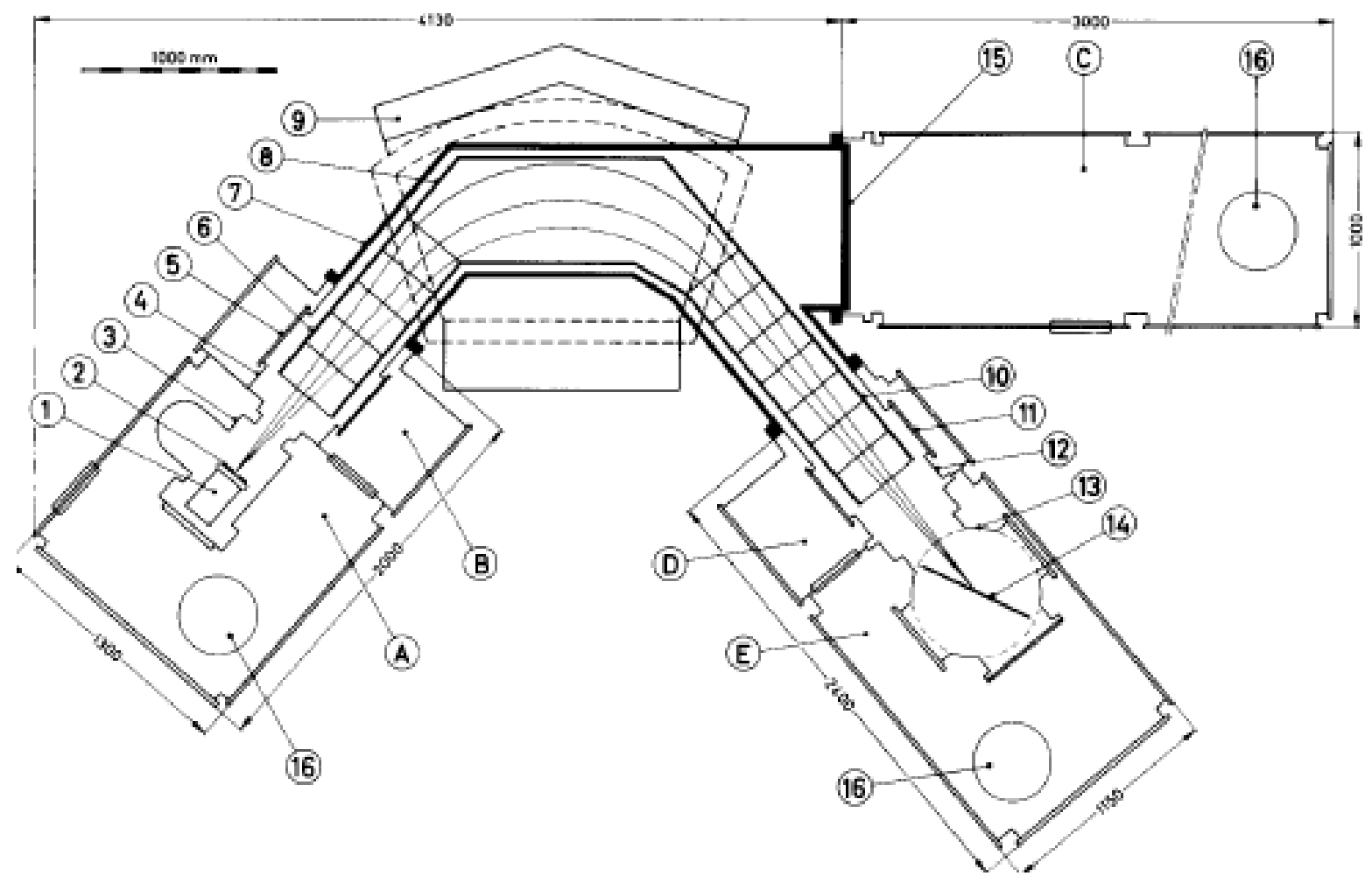

1. Ion source

2. Accelerating electrode

3. Ion source chamber

4. Beam tube connecting ion source and magnet chamber

5. Port for access to liner elements on the source side

6. Liner elements on the source side

7. Magnet chamber

8. Liner in magnet chamber

9. Magnet

10. Liner elements on the collector side

11. Port for access to liner elements on the collector side

12. Beam tube connecting collector and magnet chamber

13. Collector chamber

14. Focal plane

15. Port for access to magnet chamber liner

16. Transfer hole

A. Ion source glove box

B. Liner glove box

C. Glove box for magnet chamber liner

D. Liner glove box

E. Collector glove box

Fig. 9. Concept for an actinide isotope separator (Berg et al. 1985). 


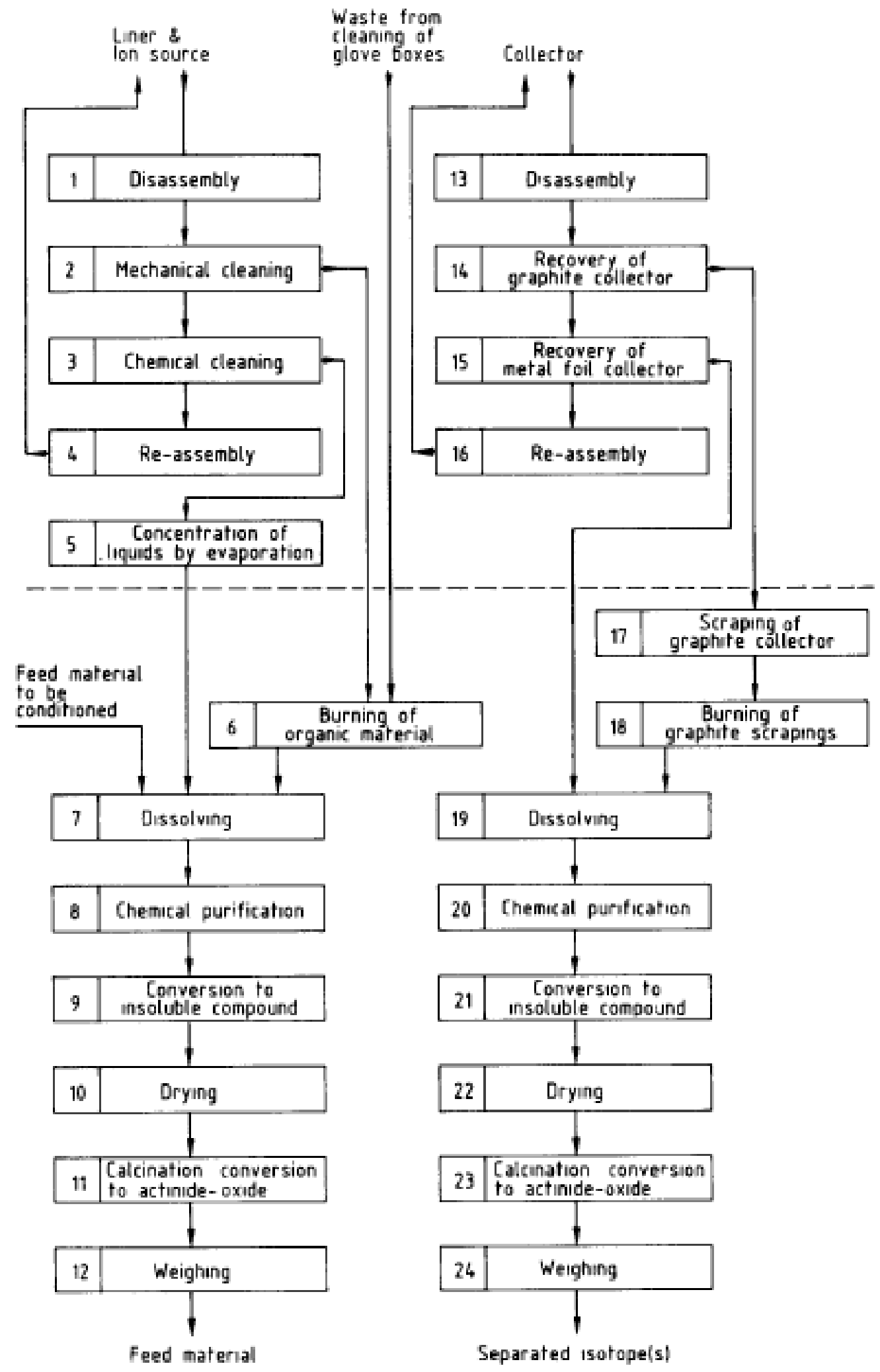

Fig. 10. Sequence of operations in an actinide handling facility (Berg et al. 1985). 
also waste from the glove boxes and any feed material that needs conditioning or purification before it can be introduced into the ion source. On the right are the operations related to the recovery and processing of the separated isotopes. Above the dotted line are the operations (steps 1 to 5 and 13 to 16) dealing with the handling of parts of the separator. Below the dotted line are the operations dealing with the processing of the actinide product material.

A proposed layout for the actinide enrichment facility is shown in Fig. 11. The glove boxes are indicated by roman numbers I to XI. The glove boxes indicated by capitals A to E constitute the alpha containment of the isotope separator corresponding to Fig. 9. The operations to be carried out in the glove boxes are indicated by Arabic numbers corresponding to Fig. 10.

\subsection{CROSS CONTAMINATION}

Since cross contamination by alpha emitters after enrichment is a concern, product recovery from the collectors should be done in a campaign mode with the most cross-contamination sensitive isotope being recovered first, followed by thorough cleaning of the glove boxes and recovery of the next isotope from the enrichment campaign. This will require the capability to store enriched, but unrecovered, collectors until each isotope recovery campaign is completed. 

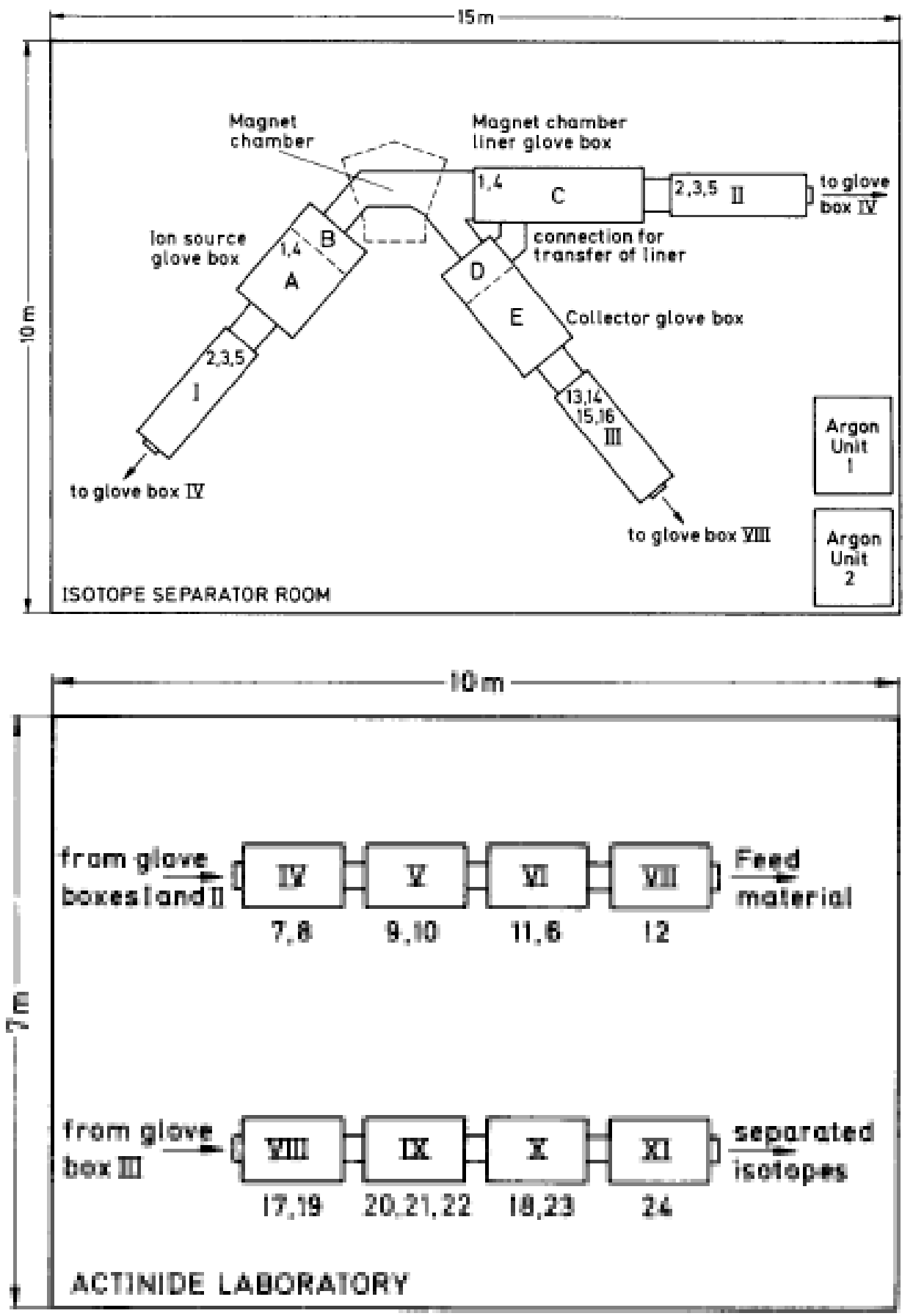

Fig. 11. Concept for equipment layout for an actinide handling facility (Berg et al. 1985). 



\section{CONCLUSIONS}

Because the capability to enrich milligram-to-gram quantities of actinide radioisotopes no longer exists in the United States, the enriched actinide requirements of the nation are currently not being met or are being met using existing, but diminishing, US inventories and foreign (mostly Russian) sources where available. Attempts for over two decades to have foreign facilities enrich US feedstock have been unsuccessful. New enrichment capabilities are, therefore, needed to provide a national actinide enrichment capability to produce milligram-to-gram quantities of unique materials to support national security, nuclear nonproliferation, and basic research programs. The most mature technology identified for supplying the milligram-to-gram quantities of enriched actinides to these specified user communities is the EMIS technology. Past actinide enrichment experience and advances in the EMIS technology applied in stable isotope separations should be leveraged with this new evaluation information to assist in the establishment of a domestic actinide radioisotope enrichment capability.

The EMIS technology is the only technology that has been successfully demonstrated for enrichment of the actinides of interest, and it is the most flexible technology for meeting additional actinide demands in the future. Recent advances in EMIS technology that are being investigated at prototype scales for production of very small quantities of materials, primarily stable isotopes, should be considered for the next generation actinide EMIS equipment to increase the efficiency and reduce the cost of production of enriched actinides compared to the World War II era systems. The conclusions of this report are consistent with the DOE/National Science Foundation Nuclear Science Advisory Committee's recommendations for reestablishing the domestic capability for production of high purity radioactive isotopes to support research needs (US DOE 2015).

. Pre-enrichment and/or post-enrichment technologies, such as irradiation, should also be considered for future applications within a national program to increase the throughput, reduce losses of material, and/or reduce operational costs of the basic EMIS enrichment system. In particular, these technologies should be considered for products requiring ultra-high purity where more than one pass through the EMIS would be required to meet the user requirements. 



\section{REFERENCES}

Abramychev, S. M. et al. (1992), "Electromagnetic Separation of Actinide Isotopes," Nuclear Instruments and Methods in Physics Research, B70: 5-8.

Berg, M. V. D. et al. (1985), "The Feasibility of Electromagnetic Actinide Isotope Separation in the European Community," Nuclear Instruments and Methods in Physics Research, A236: 463473.

Bigelow, T. S. et al. (2005), "Production of Stable Isotopes Utilizing the Plasma Separation Process,” Nuclear Instruments and Methods in Physics Research, B241: 652-654.

Carney, K. P. et al. (2012), “Advancement of Isotope Separation for the Production of Reference Standards,” J. Radioanal Nucl Chem, 296: 383-387.

Deron, S. and Vesnovskii, S. (1999) "Development of Technology for High-purity ${ }^{244} \mathrm{Pu}$ Production by Method of Electromagnetic Separation,” Nuclear Instruments and Methods in Physics Research, A438: 20-22.

Egle, B. J. (2014), "Stable Isotope Enrichment and Separations," $18^{\text {th }}$ Symposium on Separation Science and Technology for Energy Applications, October 27.

Egle, B. J. et al. (2014), "Stable Isotope Enrichment Capabilities at Oak Ridge National Laboratory,” J Radioanal Nucl Chem, 299: 995-999.

Engle, J. W. et al. (2013), “Purification of ${ }^{242}$ Pu by Irradiation with Thermal Neutrons,” Nuclear Instruments and Methods in Physics Research, B298: 70-75.

Hart, K. J. et al (2015), "Development of a Pilot Scale Facility for Production of Enriched Stable Isotopes,” The International Chemical Congress of Pacific Basin Societies 2015, December 15.

Horkley, J. J. et al. (2015), "Production of Highly-Enriched ${ }^{134}$ Ba for a Reference Material for Isotope Dilution Mass Spectrometry Measurements,” J. Radioanal Nucl Chem, 305: 267-275.

Horkley, J. J. (2016). Personal communications.

Jerome, S. M. (2014), “The Production of Neptunium-236g,” Journal of Environmental Radioactivity, 138: 315-322.

Kaschejev, N. A., et al. (1993), "Stable Isotope Production in the Former USSR by Electromagnetic Separation Techniques," Nuclear Instruments and Methods in Physics Research, A334: 27-32. 
Larignai, C. et al. (2015), "Progress towards the Production of the ${ }^{236 \mathrm{~g}} \mathrm{~Np}$ Standard Sources and Competing Fission Fragment Production,” Radiation Physics and Chemistry, 116: 69-73.

Liezers, M. et al. (2015), “The Production of Ultra-High Purity Single Isotopes or Tailored Isotope Mixtures by ICP-MS,” International Journal of Mass Spectrometry, 376, 58-64.

Los Alamos National Laboratory/Lawrence Livermore National Laboratory (2015), Integrated Plutonium Science and Research Strategy, Los Alamos National Laboratory/Lawrence Livermore National Laboratory.

Love, L. O. (1973), “Electromagnetic Separation of Isotopes at Oak Ridge,” Science, New Series, Vol. 182, No. 4110: 343-352, October (ECI).

Moniz, E. J. (2001), “Savannah River Site Mk-18A Targets,” Excess Material Disposition Decision Memorandum No. 3, January 28.

Newman, E. (1979), “The Electromagnetic Isotope Separation Program at the Oak Ridge National Laboratory,” Nuclear Instruments and Methods, 167: 81-84.

Newman, E. (1983), “Availability of Enriched Isotopic Material for Accelerator Targets,” IEEE Transactions on Nuclear Science, Vol. NS-30, No. 2: 1573-1574.

Patton, B.D. et al. (2014), “The Need for US Actinide Enrichment Capability,” Institute of Nuclear Materials Management $55^{\text {th }}$ Annual Meeting, July 20-24.

Patton, B.D., et al. (2016), “Lessons Learned from Processing Mark-18A Targets at Oak Ridge National Laboratory,” Institute of Nuclear Materials Management $57^{\text {th }}$ Annual Meeting, July 24 28.

Pokidychev, A. and Pokidycheva, M. (1999), "Development of Stable Isotope Manufacturing in Russia,” Nuclear Instruments and Methods in Physics Research, A438: 7-10.

Romano, C. (2016), personal communications.

Roberto, J. B. et al. (2015), “Actinide Targets for the Synthesis of Super-Heavy Elements,” Nuclear Physics, 94: 99-116.

Robinson, S. M. et al. (2014), Recovery of Mark-18A Target Materials: Program Management Plan, ORNL/TM-2014/314, August.

Seko, M. et al. (1990), International Symposium on Isotope Separation and Chemical Exchange Uranium Enrichment, Tokyo, Japan, October 29 - November 1. 
Texas A\&M University (2013), Projected Need for Actinide Target Materials for Super-Heavy Element (SHE) Research (Summary), Texas A\&M University, March 12-13.

Tracy, J. G. (1989), “Isotope Separation Program-Present and Future,” Nuclear Instruments and Methods in Physics Research, A282: 261-266 (ECI).

Tracy, J. G. (1991), "Status of the Isotope Enrichment Program at Oak Ridge National Laboratory," Nuclear Instruments and Methods in Physics Research, A303: 3-8.

Tracy, J.G. and Aaron, W. S. (1993), "Stable Isotope Enrichment-Current and Future Potential," Nuclear Instruments and Methods in Physics Research, A334: 45-50.

Tracy, J. G. et al. (1987), "Stable Isotope Enrichment Techniques and ORNL Separation Status," Nuclear Instruments and Methods in Physics Research, B26: 7-11.

Tracy, J. G. and Terry, J. W. (1985), "Availability of Enriched Isotopic Materials Used For Accelerator Targets-Present and Future," Nuclear Instruments and Methods in Physics Research, B10/11: 972-975.

U.S. Department of Energy (1997), Hazard Categorization and Accident Analysis Techniques for Compliance with DOE Order 5480.23, Nuclear Safety Analysis Reports, Washington, D.C., September.

U.S. Department of Energy (2015), Meeting Isotope Needs and Capturing Opportunities for the Future: The 2015 Long Range Plan for the DOE-NP Isotope Program, Washington, D.C., July.

U.S. Department of Energy (2016), The President's Budget for Fiscal Year 2017, Washington, D.C., February.

Vesnovskii, S. P. (2003), "RFNC-VNIIEF Capabilities to Production High Pure Isotopes for Scientific and Medical Applications," Journal of Radioanalytical and Nuclear Chemistry, Vol. 257, No. 1: 27-31.

Vesnovskii, S. P. (2004), "Recent Achievement in Increasing the Electromagnetic Separation Efficiency of Actinides,” Isotopes in Environmental Studies Aquatic Forum 2004, Monaco.

Vesnovskii, S. P. et al. (1992), "Highly Enriched Isotope Samples of Uranium and Transuranium Elements for Scientific Investigation,” Nuclear Instruments and Methods in Physics Research, A321: 1-4.

Vesnovskii, S. P. et al. (1996), "Capabilities of Superpure Actinide and Stable Isotope Product in Russian Federal Nuclear Center,” Journal of Radioanalytical and Nuclear Chemistry, Articles, Vol. 205, No. 1: 105-112. 
Whitehead, T. W. and White, F.A. (1972), "Design Considerations for the RPI Three-Stage Separator,” Nuclear Instruments and Methods, 103: 437-445. 
